\title{
Granule Cell Ascending Axon Excitatory Synapses onto Golgi Cells Implement a Potent Feedback Circuit in the Cerebellar Granular Layer
}

\author{
Elisabetta Cesana, ${ }^{1 \star}$ Katarzyna Pietrajtis, $, 3,3 \star$ Céline Bidoret, ${ }^{2,3,4}$ Philippe Isope, ${ }^{5}$ Egidio D’Angelo, ${ }^{1,6}$ \\ Stéphane Dieudonné, ${ }^{2,3,4}$ and Lia Forti ${ }^{7,8}$ \\ ${ }^{1}$ Brain Connectivity Center, Istituto di Ricovero e Cura a Carattere Scientifico C. Mondino, 27100 Pavia, Italy, ${ }^{2}$ École Normale Supérieure, Institut de \\ Biologie de l'ENS, IBENS, Paris, F-75005 France, ${ }^{3}$ Inserm U1024, Paris, F-75005 France, ${ }^{4}$ Centre Nationale de la Recherche Scientifique, UMR 8197 , Paris, \\ F-75005 France, ${ }^{5}$ Institut des Neurosciences Cellulaires et Intégratives, Centre Nationale de la Recherche Scientifique UPR 3212, 67084 Strasbourg, France, \\ ${ }^{6}$ Department of Brain and Behavioral Sciences, Neurophysiology Unit, University of Pavia, 27100 Pavia, Italy, ${ }^{7}$ Center for Neuroscience and Department of \\ Theoretical and Applied Sciences, Biomedical Division, University of Insubria, 21052 Busto Arsizio, Italy, and ${ }^{8}$ Department of Cellular and Molecular \\ Physiological and Pharmacological Sciences, University of Pavia, 27100 Pavia, Italy
}

The function of inhibitory interneurons within brain microcircuits depends critically on the nature and properties of their excitatory synaptic drive. Golgi cells (GoCs) of the cerebellum inhibit cerebellar granule cells (GrCs) and are driven both by feedforward mossy fiber ( $m f$ ) and feedback GrC excitation. Here, we have characterized GrC inputs to GoCs in rats and mice. We show that, during sustained $m f$ discharge, synapses from local GrCs contribute equivalent charge to GoCs as $m f$ synapses, arguing for the importance of the feedback inhibition. Previous studies predicted that GrC-GoC synapses occur predominantly between parallel fibers ( $p f s)$ and apical GoC dendrites in the molecular layer (ML). By combining EM and $\mathrm{Ca}^{2+}$ imaging, we now demonstrate the presence of functional synaptic contacts between ascending axons $(\mathrm{a} a)$ of $\mathrm{GrCs}$ and basolateral dendrites of GoCs in the granular layer (GL). Immunohistochemical quantification estimates these contacts to be $\sim 400$ per GoC. Using $\mathrm{Ca}^{2+}$ imaging to identify synaptic inputs, we show that EPSCs from $a a$ and $m f$ contacts in basolateral dendrites display similarly fast kinetics, whereas $p f$ inputs in the ML exhibit markedly slower kinetics as they undergo strong filtering by apical dendrites. We estimate that approximately half of the local GrC contacts generate fast EPSCs, indicating their basolateral location in the GL. We conclude that GrCs, through their a a contacts onto proximal GoC dendrites, define a powerful feedback inhibitory circuit in the GL.

\section{Introduction}

Golgi cells (GoCs) constitute the only source of inhibition to cerebellar granular cells (GrCs) (Eccles et al., 1967; Hamann et

Received Feb. 8, 2013; revised June 5, 2013; accepted June 14, 2013.

Author contributions: E.D., S.D., and L.F. designed research; E.C., K.P., C.B., P.I., S.D., and L.F. performed research; E.C., K.P., C.B., P.I., S.D., and L.F. analyzed data; S.D. and L.F. wrote the paper.

This work was supported by the European Union Grants SENSOPAC, FP6-IST028056, CEREBNET FP7-ITN238686, and REALNETFP7-ICT270434 to E.D. and ANR Grants 09-MNPS-038Cecomod and 11-BSV4-010 Innet to S.D. K.P was supported by CEREBNET FP7-ITN238686. E.C. was supported by the 20072CN2HP_002 of the Italian Ministero dell'Università e della Ricerca. Preliminary versions of this work were presented at the 2009 Society for Neuroscience Meeting (Chicago), at the 2010 Meeting of the Federation of European Neuroscience Societies (Amsterdam), and at the 2011 Meeting of the Italian Group for Cooperation in Molecular Neurosciences (Rome). We thank Eric Schwartz and Riccardo Fesce for helpful discussion and for critically reading the manuscript, as well as Maurizio Rossin and Gabriele Ferrari for technical assistance.

The authors declare no competing financial interests.

*E.C. and K.P. contributed equally to the study.

Correspondence should be addressed to either of the following: Dr. Lia Forti, Department of Theoretical and Applied Sciences, Biomedical Division, University of Insubria, Via A. da Giussano 10, 21052 Busto Arsizio, Italy, E-mail: lia.forti@uninsubria.it; or Dr. Stéphane Dieudonné, Inhibitory Transmission Team, Institut de Biologie de I'ENS, IBENS, 46 rue d'Ulm, 75005 Paris, France. E-mail: dieudon@biologie.ens.fr.

E. Cesana's present address: Department of Biology and Biotechnology “L. Spallanzani," University of Pavia, and Department of Pharmacological Sciences and Center for Stem Cell Research, University of Milano, Milan, Italy.

C. Bidoret's present address: Laboratoire de Neurophysiologie et nouvelles Microscopies, INSERM U603, Université Paris Descartes, Paris, France.

DOI:10.1523/JNEUROSCI.4897-11.2013

Copyright $\odot 2013$ the authors $\quad 0270-6474 / 13 / 3312430-17 \$ 15.00 / 0$ al., 2002; Crowley et al., 2009), and their acute ablation causes severe ataxia (Watanabe et al., 1998). GoCs may control GrC excitation by performing lateral inhibition and gain control (Eccles et al., 1967; Marr, 1969; Albus, 1971), by creating oscillatory synchronization (Maex and De Schutter, 1998; Dugué et al., 2009; Vervaeke et al., 2010), by setting the time window for GrC excitation (D'Angelo and De Zeeuw, 2009), and by controlling long-term synaptic plasticity at mossy fiber $(m f)$ synapses (Mapelli and D'Angelo, 2007).

GoC function shall ultimately depend on its synaptic connections within the cerebellar microcircuit. GoCs receive excitatory synaptic contacts from $m f s$ (Kanichay and Silver, 2008), participating in a feedforward inhibitory circuit (Eccles et al., 1967; Katz, 1969). In addition, GrC to GoC synapses have been described morphologically (Eccles et al., 1967; Palay and ChanPalay, 1974) and electrophysiologically (Dieudonné, 1998; Bureau et al., 2000; Misra et al., 2000; Watanabe and Nakanishi, 2003; Beierlein et al., 2007; Menuz et al., 2008; Robberechts et al., 2010). This connection is often described as a feedback circuit, as GrCs and GoCs excite and inhibit each other, respectively. However, GoC axons extend mainly parasagittally (transverse extension $180 \mu \mathrm{m}$ ) (Barmack and Yakhnitsa, 2008), whereas GrC 
axons, the parallel fibers ( $p f s)$, extend for several millimeters in the transverse plane (Pichitpornchai et al., 1994). Thus, whereas inputs from local GrCs might implement feedback inhibition within a parasagittally oriented cerebellar module (Sillitoe et al., 2008; Apps and Hawkes, 2009), $p f$ inputs from distal GrCs may mediate lateral inhibition between cerebellar modules.

In vivo, GoC firing is modulated by sensory inputs (Vos et al., 1999a; Holtzman et al., 2006; Barmack and Yakhnitsa, 2008; Xu and Edgley, 2010), sensorimotor activity (Edgley and Lidierth, 1987; van Kan et al., 1993; Prsa et al., 2009; Heine et al., 2010), and cortical up- and down-states (Ros et al., 2009). Punctuate peripheral stimuli may produce biphasic excitation (Vos et al., 1999a; Holtzman et al., 2006; Xu and Edgley, 2008, 2010), attributed to either direct $m f$ or disynaptic GrC inputs (Vos et al., 1999a). Convergence of $p f$ excitation from many modules was proposed to produce the broad receptive fields of GoCs (Vos et al., 1999a; Holtzman et al., 2006; Prsa et al., 2009; Heine et al., 2010; Holtzman et al., 2011) as well as longitudinal GoC firing synchronization (Vos et al., 1999b). Hence, the existence of a specific local feedback circuit onto GrCs has not been previously established.

We show here, by light and EM immunocytochemistry, that $\mathrm{GrC}$ ascending axons form numerous synaptic contacts onto GoC basolateral dendrites in the same parasagittal module. Combining white matter (WM) stimulations and ultrafast 2-photon $\mathrm{Ca}^{2+}$ imaging in GoC basolateral dendrites, we reveal activity of this synaptic articulation, which is involved in a powerful feedback circuit. These contacts represent a large fraction of overall local GrC inputs and therefore form an important feedback pathway in the modular organization of the granular layer $(\mathrm{GL})$.

\section{Materials and Methods}

\section{Slice preparation and maintenance}

Sagittal or parasagittal slices ( $220 \mu \mathrm{m}$ thick) were cut from the cerebellar vermis of 17- to 22-day-old (P17-P22) Wistar rats of either sex, decapitated after deep anesthesia with halothane or chloroform. All experimental procedures were approved by the Ethical Committee of the University of Pavia, the Italian Health Office, and conformed to the procedural guidance by the Centre Nationale de la Recherche Scientifique. Slices were cut by means of a microslicer (Dosaka, Microm). During slicing, the tissue was immersed in an ice-cold $\left(2-3^{\circ} \mathrm{C}\right)$ solution containing the following (in $\mathrm{mM}$ ): 130 potassium gluconate, $15 \mathrm{KCl}, 0.2 \mathrm{EGTA}, 20 \mathrm{HEPES}$, 10 glucose, adjusted to pH 7.4 with $\mathrm{NaOH}$ (Dugué et al., 2005). They were either transiently immersed in a mannitol-based solution containing the following (in mM): $225 \mathrm{D}$-mannitol, $2.5 \mathrm{KCl}, 1.25 \mathrm{NaH}_{2} \mathrm{PO}_{4}, 25$ $\mathrm{NaHCO}_{3}, 25$ glucose, $0.8 \mathrm{CaCl}_{2}$, and $8 \mathrm{MgCl}_{2}$ or directly transferred to standard extracellular solution ("control saline"), containing the following (in mM): $120 \mathrm{NaCl}, 2 \mathrm{KCl}, 1.2 \mathrm{MgSO}_{4}, 26 \mathrm{NaHCO}_{3}, 1.2 \mathrm{KH}_{2} \mathrm{PO}_{4}, 2$ $\mathrm{CaCl}_{2}, 11$ glucose, at $\mathrm{pH} 7.4$ when bubbled with $95 \% \mathrm{O}_{2}$ and $5 \% \mathrm{CO}_{2}$; in imaging experiments, $\mathrm{MgSO}_{4}$ was replaced by $1 \mathrm{~mm} \mathrm{MgCl}_{2}$. All experiments were performed at $31-33^{\circ} \mathrm{C}$. During recordings, slices were placed in a recording chamber continuously perfused at a rate of $1.5 \mathrm{ml} / \mathrm{min}$ with oxygenated control saline. SR 95531 (gabazine; $10 \mu \mathrm{M}$ ) and strychnine ( $500 \mathrm{~nm}$ ) were routinely added to the bath solution to block inhibitory synaptic inputs, unless otherwise stated.

\section{Electrophysiological apparatus}

Slices were visualized using an upright epifluorescence microscope (Axioskop 2 FS, Carl Zeiss) equipped with a $63 \times$, 0.9 NA water-immersion objective, and differential interference contrast optics, using infrared illumination (IR; excitation filter $750 \mathrm{~nm}$ ) and an IR CCD camera (Till Photonics). GoCs were visually selected in the cerebellar granular layer by their large soma; the identification of GoCs was confirmed by their passive electrical properties (Dieudonné, 1998; Forti et al., 2006). Pipettes were fabricated with a Sutter P-97 horizontal puller (Sutter Instruments) from thick-walled borosilicate glass capillaries $(0.15 \mathrm{~mm}$ diameter; Hilgenberg). Recordings were obtained using an Axopatch
200B, a Multiclamp 700A or a Multiclamp 700B amplifier and converted by a Digidata 1320 A or 1440 A interface (Molecular Devices). All data were acquired with Clampex (Molecular Devices).

\section{Whole-cell recordings}

For whole-cell recordings of GoC EPSCs in the voltage-clamp configuration, pipettes were filled with one of the following internal solutions: (1) K-Gluconate, containing the following (in $\mathrm{mM}$ ): 135 or 145 potassium gluconate, $5 \mathrm{KCl}, 10 \mathrm{HEPES}, 0.2 \mathrm{EGTA}, 4.6 \mathrm{MgCl}_{2}, 4 \mathrm{ATP}-\mathrm{Na}_{2}, 0.4$ GTP-Na ${ }_{2}$, adjusted at pH 7.35 with $\mathrm{KOH}$; (2) K-methylsulfate, containing the following (in mM): $135 \mathrm{KMeSO}_{4}, 10 \mathrm{HEPES}, 0.1 \mathrm{EGTA}, 3 \mathrm{MgCl}_{2}$, 2 ATP-Na 2 , 2 ATP-Mg, 0.4 GTP-Na $\mathrm{Na}_{2}$; (3) K-methylsulfate-II, used in imaging experiments, containing the following (in mM): $150 \mathrm{KMeSO}_{4}, 6$ $\mathrm{NaCl}, 2 \mathrm{MgCl}_{2}, 10$ HEPES, 4 ATP-Mg, 0.4 GTP- $\mathrm{Na}_{2}$, adjusted at $\mathrm{pH} 7.35$ with $\mathrm{KOH}$; or (4) Cs-BAPTA, containing the following (in $\mathrm{mM}$ ): 81 $\mathrm{CsSO}_{4}, 4 \mathrm{NaCl}, 15$ HEPES, $2 \mathrm{MgSO}_{4}, 0.15$ BAPTA, 3 ATP-Mg, 0.1 GTP$\mathrm{Na}_{2}$, and 15 glucose, adjusted at $\mathrm{pH} 7.2$ with $\mathrm{CsOH}$. The last solution was designed to block the activation of voltage-dependent conductances at depolarized potentials and was used mainly for the study of the NMDA component of EPSCs. In all Cs-BAPTA recordings, and in part of the K-gluconate recordings, internal solutions were supplemented with $5 \mathrm{~mm} N$-(2,6-dimethylphenylcarbamoylmethyl)-triethylammonium (QX-314) to prevent unclamped spiking. The liquid junction potential with respect to control saline was $10 \mathrm{mV}$ with K-Gluconate, $8 \mathrm{mV}$ with $\mathrm{K}$-methylsulfate and $\mathrm{K}$-methylsulfate-II, and $9.5 \mathrm{mV}$ with Cs-BAPTA solution; membrane potential $\left(\mathrm{V}_{\mathrm{m}}\right)$ was accordingly corrected throughout the text. Pipettes were coated with dental wax and had a resistance of 3-5 $\mathrm{M} \Omega$ when immersed in the bath. Signals were low-pass filtered at $10 \mathrm{kHz}$ and acquired at $50 \mathrm{kHz}$. Recordings were discarded when the basal current at $-70 \mathrm{mV}$ was negative to $-150 \mathrm{pA}$. Series resistance $\left(R_{s}\right)$ was in the range $4-20 \mathrm{M} \Omega$, constantly monitored during recordings and compensated by $65-90 \%$; in analyzed recording periods, $\mathrm{R}_{\mathrm{S}}$ was constant within $10 \%$.

\section{Stimulation}

To record $m f$-EPSCs and GrC-EPSCs (from $m f$-GoC and GrC-GoC inputs, respectively), the $m f$ bundle was stimulated using a large-bore (3-10 $\mu \mathrm{m}$ diameter) patch pipette, connected to a stimulus isolation unit and filled either with control saline, or with a HEPES-buffered extracellular saline (no appreciable differences between the two solutions). Individual stimuli were $200 \mu$ s monopolar square pulses. The stimulation pipette was positioned in the WM in an appropriate position to evoke monosynaptic $m f$ inputs and disynaptic GrC inputs, as follows. A pipette positioned near to the recorded GoC (see Fig. $1 B$, pipette "A") may evoke short-latency monosynaptic inputs from either $m f s$ or GrCs, through pathways 1 and 2 in Figure $1 B$. Indeed, the stimulus may not only activate $m f$ s, running in the WM to enter cerebellar folia, but also evoke spikes in GrC axons near the WM (as assessed in loose-cell attached recordings from $\mathrm{GrC}$ somata in the presence of NBQX; data not shown). However, in parasagittal slices, a GoC receives direct contacts only from GrCs in the longitudinal volume delimited by its dendritic arbor (see Fig. $1 B$, shaded area). Therefore, a stimulation pipette at sufficient distance from the recorded GoC (see Fig. $1 B$, pipette " $B$ ") may activate monosynaptic inputs exclusively from $m f s$, which extend parasagittally in the WM and cross the border of the $\mathrm{GoC}$ dendritic territory, whereas $\mathrm{GrC}$ inputs are disynaptic (see Fig. $1 B$, pathways 3 and 4). In conclusion, the distance between stimulus and the soma of the recorded $\mathrm{GoC}$ was always set to exceed $300 \mu \mathrm{m}$, well above the extension of the apical GoC dendritic arbor (150 $\mu \mathrm{m}$ on each side of the cell body) (Dieudonné, 1998).

Paired-pulse stimulation consisted of two stimuli, separated by $10 \mathrm{~ms}$, and repeated every $10 \mathrm{~s}$. The "minimal stimulation" protocol, designed to isolate the response to a single mossy fiber, consisted of runs of 10-50 stimuli, delivered at $0.1 \mathrm{~Hz}$, for each one of a range of strengths, from just subthreshold (median, $7 \mathrm{~V}$ ) to $\sim 10$-fold larger values; the runs were given in random sequence.

\section{Paired recordings}

To study the GrC-GoC connection in paired recordings, GrCs located within a few tens of micrometers of the GoC body were specifically stim- 
ulated in the loose-cell attached configuration. This technique excluded activation of nearby $m f s$. The loose-cell attached configuration was obtained on $\mathrm{GrC}$ bodies using a 3-5 $\mathrm{M} \Omega$ patch pipette. Large positive voltage jumps were applied to depolarize the $\mathrm{GrC}$ to threshold through its membrane capacitance while recording the $\mathrm{GrC}$ juxtacellular spikeinduced current (Barbour and Isope, 2000). Simultaneous failure of the juxtacellular spike and of the evoked EPSC in the GoC at near-threshold stimulation was the criterion used to exclude a possible contamination by stimulation of nearby cells and fibers. GoCs were recorded with the Cs-BAPTA internal solution.

\section{Drug application}

Strychnine hydrochloride was obtained from Sigma. All other drugs were from Tocris Bioscience: QX-314, D-APV, NBQX, and 6-imino-3-(4methoxyphenyl)-1(6H)-pyridazinebutanoic acid hydrobromide (SR 95531, gabazine). Stock solutions were prepared in water and stored at $-20^{\circ} \mathrm{C}$. During experiments, aliquots were diluted in control saline and bath-applied.

\section{Analysis of synaptic currents}

Latency distributions. To study the latency distributions of evoked EPSCs (see Fig. 1), synaptic currents were detected in the $10 \mathrm{~ms}$ window after a stimulus using a threshold-above-baseline detector (Kudoh and Taguchi, 2002) implemented in the NeuroMatic package (J. Rothman, http://www.neuromatic.thinkrandom.com/), and their latency from stimulus onset was measured. To demonstrate the presence of an evoked disynaptic response, the number $\left(N_{\mathrm{obs}}\right)$ of EPSCs observed in the time window between 2.5 and $10 \mathrm{~ms}$ after the stimulus in $N$ trials was compared with the number of spontaneous EPSCs expected to occur randomly in the same interval $\left(\mu=f_{s} \times(7.5 \mathrm{~ms}) \times N\right)$, where $f_{s}$ is the observed sEPSC frequency. The probability that $N_{\text {obs }}$ sEPSCs occurred by chance in the late time window $(>2.5 \mathrm{~ms})$ is given by the area under the tail of the Poisson distribution with parameter $\mu$ and $n \geq N_{\text {obs }}$. Whenever this probability was $<10^{-4}$, evoked disynaptic long-latency (LL) EPSCs were acknowledged. In latency histograms, multiple peaks (usually two $)$ were always clearly separated by a short $(\sim 0.5 \mathrm{~ms})$ interval with no events. Events were visually assigned to the first or second peak, and the SD of the latencies in each group was used as a measure of peak dispersion.

Waveform analysis. The waveform of evoked $m f$ - and GrC-EPSCs was analyzed using Clampfit 10 (Molecular Devices) or a home-made detection and analysis routine running in IGOR (Wavemetrics). Current traces were baseline-subtracted. EPSC detection was performed in the 10 $\mathrm{ms}$ window after each stimulus. Events in the time window corresponding to the early narrow peak of the EPSC latency histogram (typically between 1.4 and $2.5 \mathrm{~ms}$ after stimulus; see Fig. $1 C-F$ ) were classified as short-latency (SL)-EPSCs (identified with $m f$-EPSCs); those detected in the rest of the interval as LL-EPSCs (identified with GrC-EPSCs). For detection, the peak of a candidate EPSC, defined as the mean current over $300 \mu$ s around a local minimum, was evaluated; an EPSC was acknowledged when this peak was $>3 \mathrm{SD}$ of the baseline current noise in a $2 \mathrm{~ms}$ window before stimulus.

For EPSC kinetics, the $20-80 \%$ rise time $\left(t_{20-80}\right)$ and the decay time constant(s) were studied. $t_{20-80}$ was measured on each individual trace, whereas the decay phase was studied both in individual traces (Fig. $7 D, E)$, and in averages. To average LL-EPSCs, events were aligned on the time of $20 \%$ rise; for SL-EPSCs, traces were aligned on the time of the stimulus. In the latter case, the latency jitter of individual responses is expected to significantly affect the rising, but not the decaying phase of the average. The decay was fitted, starting at $90 \%$ of peak amplitude, with 1-2 exponentials using nonlinear least-squares methods to yield one $(\tau)$ or two $\left(\tau_{\text {fast }}, \tau_{\text {slow }}\right)$ decay time constants and their respective amplitudes $\left(A ; A_{\text {slow }}, A_{\text {fast }}\right)$. The slow component was considered absent when $\tau_{\text {slow }}<3 \times \tau_{\text {fast }}$ or when it had negative or irrelevant amplitude ( $\leq 2 \%$ of $\left.\mathrm{A}_{\text {fast }}\right)$. The fit was performed over 5-9 ms after the peak, with the exception of the fits in Fig. 7D, E. Two exponential components, when present, were only found in average traces (see Fig. 6A), whereas in the corresponding individual traces the second, slow component was not detected, most likely buried by noise.
For the comparative analysis of amplitude and kinetics of $m f$-EPSCs and GrC-EPSCs (see Fig. $7 D, E$ ), we selected all the isolated events in the first $2.5 \mathrm{~ms}$ after each stimulus and in the subsequent $7.5 \mathrm{~ms}$, respectively. To maximize the number of analyzable $m f$-EPSCs while avoiding crosscontamination, a weighted time constant $\left(\tau_{\mathbf{w}}\right)$ was measured in 1.2-2.4 $\mathrm{ms}$ after the peak (starting at $90 \%$ peak amplitude). For $m f$-EPSCs, $\tau_{\mathrm{w}}$ was equivalent to the fast decay time constant obtained when fitting over longer time windows (see Fig. $6 A-C$ ). The 8 minimal stimulation experiments used for this analysis were selected with the requirement of a sufficient number (12-84) of well-isolated GrC-EPSCs, to allow waveform analysis. Within this selection, the coefficient of variation of $20-$ $80 \%$ rise times $\left(\mathrm{CV}_{\text {rise }}\right)$ of GrC-EPSCs was not significantly different from $\mathrm{CV}_{\text {rise }}$ of $m f$-EPSCs, whereas both were significantly smaller than $\mathrm{CV}_{\text {rise }}$ of spontaneous EPSCs (sEPSCs) ( $m f$-EPSCs, $0.36 \pm 0.12$; GrCEPSCs, $0.42 \pm 0.13$; sEPSCs, $0.75 \pm 0.27$, mean $\pm \mathrm{SD}, n=8$ cells; $\mathrm{P}_{\text {GrC/sEPSC }}<0.05 ; \mathrm{P}_{\text {mf } / \text { sEPSC }}<0.01 ; \mathrm{P}_{\text {GrC-/mf-EPSC }}>0.05$, nonparametric ANOVA), suggesting that $m f$ - and GrC-EPSCs were generated in a few contacts at well-defined electrotonic distance, whereas sEPSCs reflected the activity of several synapses at variable distances from the GoC soma.

In whole-cell recordings aimed at identifying pharmacological components of the $m f$-EPSC (see Fig. $1 H-J$ ), all parameters were measured on averages from a few tens of individual responses, selected to exclude disynaptic GrC-EPSCs.

\section{Two-photon $\mathrm{Ca}^{2+}$ imaging}

All experiments were performed with a custom-built random-access two-photon laser-scanning microscope (Otsu et al., 2008). In this instrument, both $\mathrm{X}$ and $\mathrm{Y}$ scanning are operated by acousto-optic deflectors (AODs). These custom-built nonmechanical beam-steering devices (A-A Opto-Electronic) can redirect the laser beam in $6.5 \mu \mathrm{s}$. Twophoton excitation was produced by an infrared Ti-Sa pulsed Tsunami laser pumped by a Millennia VI (Spectra-Physics) and coupled to the transmitted light port of a BX51W1 microscope (Olympus). The microscope was equipped with a $40 \times$ LUMPlanFL/IR objective with $0.8 \mathrm{nu}-$ merical aperture (Olympus). Fluorescence photons were detected by a cooled AsGaP H7421-40 photomultiplier (Hamamatsu). To operate the AODs and run the scanning procedures, a custom-made user interface was programmed in LabView (National Instruments). The AOD acoustic frequency drive was generated by a Direct Digital Synthesizer and a fast (10 ns) power amplifier (A-A Optoelectronics).

GoCs were filled through the whole-cell patch pipette with the morphological dye Alexa-594 (15 $\mu \mathrm{M}$; Invitrogen) and the high-affinity $\mathrm{Ca}^{2+}$ dye Fluo-4 (200 $\mu \mathrm{M}$; Invitrogen). Cells were clamped at $-68,-73$, or $-78 \mathrm{mV}$. For GL imaging (see Fig. 4), after evoking stable unitary $m f$ EPSCs with minimal electrical stimulation in the WM (as above) at 0.2 $\mathrm{Hz}, \mathrm{Mg}^{2+}$ was washed away from the control saline for at least $20 \mathrm{~min}$ to remove block of NMDA receptors (NMDARs). Upon appearance of the NMDA component of the $m f$-EPSC, the dendrites were systematically scanned in the GL by performing continuous $\mathrm{Ca}^{2+}$ imaging at $\sim 10 \mathrm{~Hz}$, looking for site(s) of $m f$-evoked $\mathrm{Ca}^{2+}$ entry. For molecular layer (ML) imaging (see Fig. 6), slices were continuously bathed in control saline. The stimulation electrode, filled with a HEPES-buffered solution and Alexa-594, was placed at the surface of the slice, well above a deeprunning $\mathrm{GoC}$ apical dendrite, to avoid direct dendrite stimulation. The distance from the stimulation electrode to the imaged dendrite in the $z$-plane varied from 18 to $41 \mu \mathrm{m}$. The distance from the dendrite to the lower Purkinje cell layer in the $x-y$ plane varied between 37.5 and $117 \mu \mathrm{m}$. The presumed target apical dendrite was scanned, looking for local $\mathrm{Ca}^{2+}$ transients, whereas EPSCs were evoked by juxta-threshold stimulations at $0.5 \mathrm{~Hz}$.

Whenever the presence of a responding site in the GL or the ML was found, continuous $10 \mathrm{~Hz}$-imaging was stopped, and temporally resolved optical recordings of $\mathrm{Ca}^{2+}$ influx, at and near the presumed synaptic site, was performed by setting 15 to 25 points of interest (POIs) along the GoC dendrites with a spacing of $\sim 1 \mu \mathrm{m}$. The imaging dwell time per POI, during which fluorescence photons were collected, was set between 20 and $50 \mu$ s, yielding sampling rates comprised between 0.98 and $3.2 \mathrm{kHz}$. In this way, fast biological signals could be simultaneously resolved at multiple POIs. Episodic acquisition of $\mathrm{Ca}^{2+}$ dye fluorescence transients 
(excitation wavelength $820 \mathrm{~nm}$, emission bandpass $480-580 \mathrm{~nm}$ ) was synchronized with electrophysiological stimulation protocols to time the averaging procedure. Fluorescence acquisition was routinely interrupted every 3-5 min to correct for possible drift of the preparation. The laser power (typical averaged square power $<10 \mathrm{~mW}^{2}$ per point) provided good signal-to-noise ratio while limiting photodamage (Otsu et al., 2008). Optical recordings were stable for up to several hours, only limited by the duration of the patch recordings. $z$-stack acquisition of the Alexa594 fluorescence was performed at the end of the experiment to reconstruct cell morphology (excitation $820 \mathrm{~nm}$, emission bandpass 605-675 $\mathrm{nm}$ ). The effect of D-APV or NBQX on fluorescence responses was measured on the average of 20-30 trials, taken at least 3 min after the start of drug application.

All data were analyzed with routines developed in-house using IGOR. Fluorescence intensity transients were measured as $\Delta \mathrm{F} / \mathrm{F}_{0}=\left(\mathrm{F}-\mathrm{F}_{0}\right) / \mathrm{F}_{0}$, where $\mathrm{F}_{0}$ and $\mathrm{F}$ are the background-subtracted photon number at rest and during the test period, respectively. Background fluorescence was acquired at a POI positioned far from dye-loaded structures. A fluorescence signal was acknowledged when $\Delta \mathrm{F} / \mathrm{F}_{0}$ was larger than twice the baseline SD all along a $20 \mathrm{~ms}$ "detection" window (otherwise, a failure was declared); the initial point in this window was taken as the event start. Latency from stimulus was the interval from the mid-time of the stimulus to the event start. Averages were formed from a few tens (15-50) of trials. $\mathrm{Ca}^{2+}$ entry sites were defined as POIs where the latency and the time of $20-80 \%$ rise to peak fluorescence, evaluated from average traces, were shorter than in neighboring POIs (see Fig. $4 B, G$ ). The correct identification of the synaptic contact site was confirmed by the correlation of stimulation and imaging failures. For GL imaging, peak $\mathrm{Ca}^{2+}$ flux at a given entry site was quantified as the average $\Delta \mathrm{F} / \mathrm{F}_{0}$ over the first $7 \mathrm{~ms}$ after latency $\left(\Delta \mathrm{F}_{7 \mathrm{~ms}}\right)$, which is a measure of the initial rate of rise of fluorescence. This was preferred to evaluating peak fluorescence change because the latter is potentially affected by $\mathrm{Ca}^{2+}$ diffusion from nearby synaptic sites and out of the recorded site or by $\mathrm{Ca}^{2+}$ release phenomena, as suggested by the large variability of time-to-peak among sites (from $\sim 15$ to $\sim 80 \mathrm{~ms}$; data not shown), whereas the rate of rise of fluorescence at entry sites should be linearly correlated to the intensity of local $\mathrm{Ca}^{2+}$ influx. For molecular layer imaging, $\mathrm{Ca}^{2+}$ entry sites had stable time-topeak fluorescence change, and $\mathrm{Ca}^{2+}$ flux was quantified as the average $\Delta \mathrm{F} / \mathrm{F}_{0}$ over $20-40 \mathrm{~ms}$ after stimulation.

\section{Pre-embedding immunoelectron microscopy}

GlyT2-EGFP mice, a transgenic mouse model expressing GFP in glycinergic interneurons (P52-P65; kind gift from H.U. Zeilhofer) (Zeilhofer et al., 2005), or Wistar rats (P24), were anesthetized with pentobarbital (60 $\mathrm{mg} / \mathrm{kg}$ ) and intracardially perfused with $4 \%$ PFA and $0.1 \%$ glutaraldehyde in PBS. After dissection, the cerebellum was kept overnight at $4^{\circ} \mathrm{C}$ in $4 \%$ PFA. Vibratome sagittal sections $(100 \mu \mathrm{m})$ were collected in ice-cold PBS, cryoprotected for $3 \mathrm{~h}$ in $20 \%$ sucrose $/ 20 \%$ glycerol at room temperature, permeabilized by freezing and thawing, and then incubated overnight at $4^{\circ} \mathrm{C}$ in anti-GFP rabbit polyclonal antibody (1:50; ref 132002, Synaptic Systems) or in anti-neurogranin polyclonal antibody (1:50; ref AB5620, Millipore Bioscience Research Reagents) diluted in PBS containing $0.1 \%$ gelatin (PBSg). After extensive washes, GFP or neurogranin expression was detected by using the avidin-biotin complex method (Elite Vectastain, Vector Laboratories). For this purpose, the sections were incubated for $4 \mathrm{~h}$ at room temperature with biotinylated horse anti-rabbit antibody (1:200 in PBSg, Vector Laboratories). After a preincubation for $20 \mathrm{~min}$ in $0.6 \% \mathrm{DAB}$ in Tris-buffered saline ( $0.06 \mathrm{M}, \mathrm{pH} 7.4)$, the sections were incubated with $\mathrm{DAB}$ and hydrogen peroxide (Sigma; Fast $\mathrm{DAB}$ ) in the same buffer and revealed under visual control. They were then postfixed for $1 \mathrm{~h}$ at $4^{\circ} \mathrm{C}$ in $2 \%$ osmium tetroxide in PBS with $0.07 \%$ glucose, dehydrated in ethanol, and finally flat-embedded in Araldite resin (Polysciences). After blocks were trimmed, ultrathin sections $(\sim 70 \mathrm{~nm}$ ) were collected on copper grids and counterstained for 10 min with $2 \%$ uranyl acetate in $\mathrm{H}_{2} \mathrm{O}$ and then with $0.2 \%$ Reynolds lead citrate (Reynolds, 1963). Observations of ultrathin sections were performed with a Philips Tecnaï 12 electron microscope (FEI). Micrographs were processed and analyzed using ImageJ free software.

\section{Immunohistochemistry}

Tissue fixation. For immunohistochemistry, we used heterozygote transgenic mice of the GlyT2-EGFP line, which were backcrossed for $>10$ generations to the C57BL/6 J background. GFP is expressed in $85 \%$ of GoCs in this mouse line, the others being pure GABAergic cells (Simat et al., 2007). Two males, 2 months of age, were deeply anesthetized by intraperitoneal injection of sodium pentobarbital $(60 \mathrm{mg} / \mathrm{kg}$ body weight) and perfused through the ascending aorta with PBS, followed by $75 \mathrm{ml}$ of $4 \%$ freshly depolymerized PFA in $0.1 \mathrm{M} \mathrm{PBS}, \mathrm{pH} 7.4$, both at $4^{\circ} \mathrm{C}$. Brains were then dissected and postfixed in $4 \%$ PFA overnight at $4^{\circ} \mathrm{C}$. They were then dehydrated in a gradient of alcohol (ethanol $70 \%, 80 \%$, 95\%, 100\%) followed by butanol and xylene and embedded in paraffin (Paraplast X-TRA Tissue Embedding Medium, Leica Microsystems).

Tissue preparation and labeling. Sagittal sections (20 $\mu \mathrm{m}$ thickness) were cut on a microtome and mounted on positively charged glass slides (Superfrost Plus, Thermo Scientific). After removing paraffin with xylene and rehydration in a graded series of ethanol $(100 \%, 95 \%, 85 \%$, $75 \%, 50 \%$ ), sections were processed in a decloaking chamber (Biocare Medical) using a citrate buffer-based antigen retrieval medium (Biocare Medical) for $20 \mathrm{~min}$ at $110-115^{\circ} \mathrm{C}$. Aldehyde groups were removed by incubating the sections in sodium borohydride (1\%) in PBS. They were then processed in PBS with $15 \%$ methanol and $0.3 \% \mathrm{H}_{2} \mathrm{O}_{2}$ to block the endogenous eroxidase activity. After these treatments, the slices were incubated in a blocking PBS-based solution containing cold-water fishskin gelatin $(0.1 \%)$ and $0.1 \%$ Triton $\mathrm{X}-100$. Tissue was then incubated overnight at $4{ }^{\circ} \mathrm{C}$ with the following primary antibodies: chicken antiGFP (1:1000; Aves Laboratories), guinea pig anti-vGluT1 (1:1500; Millipore), and mouse anti-vGluT2 (1:1500; Millipore). Primary antibodies were revealed by incubation for $2 \mathrm{~h}$ with secondary antibodies coupled to either Alexa-488 (Invitrogen) or DyLight 488, DyLight 549, and DyLight 649 (Jackson ImmunoResearch Laboratories). Sections were mounted using Prolong Gold Antifade Reagent (Invitrogen).

Image acquisition and analysis. Confocal stacks were acquired on a Leica SP5 microscope using a $63 \times$ oil-immersion objective (NA 1.4) and a pinhole aperture of 1 Airy. To resolve individual synaptic boutons, data were oversampled using a voxel size of $0.06 \mu \mathrm{m}$ in $x-y$ and $0.17 \mu \mathrm{m}$ in $z$. Image stacks were analyzed in $3 \mathrm{D}$ using the software Imaris (Bitplane $A G)$. vGluT1-positive hot spots were detected in the GL using the spot function of Imaris, adjusting size and intensity thresholds to select all extraglomerular varicose-like puncta. This also led to a large number of spurious intraglomerular hits. To exclude these puncta, the fluorescence was measured on the vGluT2 channel, and regions in which all $m f s$ expressed vGluT2 were chosen. vGluT2 immunoreactivity always displayed a bimodal distribution, with a subpopulation of spots displaying only background staining (see Fig. 5D). Thresholding at twice the mode of this first population selectively highlighted extraglomerular vGluT1only varicose profiles, tentatively identified as $a a$ varicosities in the GL. GoCs, identified from the stack based on GFP immunoreactivity, were segmented using the surface function of Imaris (adaptive local thresholding). Distances were calculated between the center of putative $a a$ varicosities and the surface of GoCs, both in the original stack and in a stack for which the GFP channel had been rotated by $180^{\circ}$ to randomize the GFP signal relative to the vGluT1 signal.

\section{Statistical tests}

Data are reported as mean \pm SD unless otherwise stated. For statistical comparisons, nonparametric methods were used, and two-tailed $p$ values were computed using GraphPad Instat software (GraphPad Software). The Mann-Whitney test and the Wilcoxon matched-pairs test were used to compare the means of two groups of unpaired and paired values, respectively; one-way ANOVA was used for $>2$ groups of paired values. Correlations were studied using Spearman's rank correlation test.

\section{Results}

$m f$ and GrC excitatory synaptic inputs evoked in Golgi cells by WM stimulation

We set out to investigate the respective functional contributions of $m f$ and $\mathrm{GrC}$ synaptic inputs to the excitation of GoCs and their 


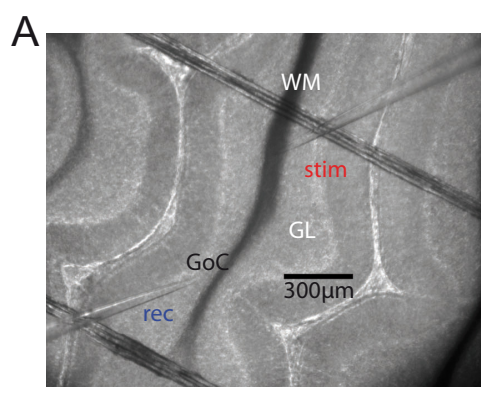

B

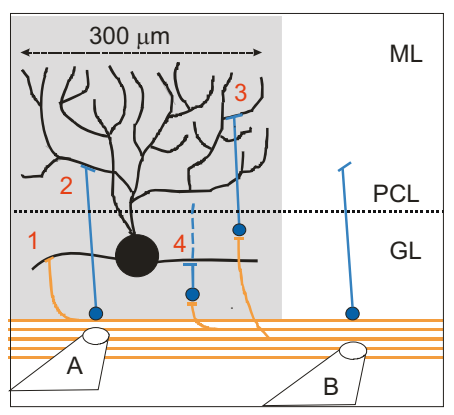

C

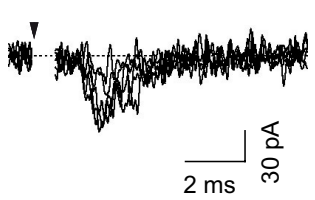

E

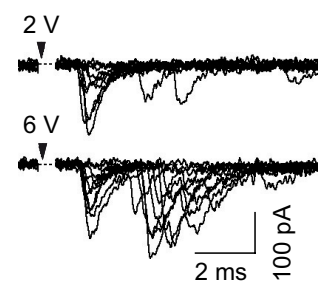

H

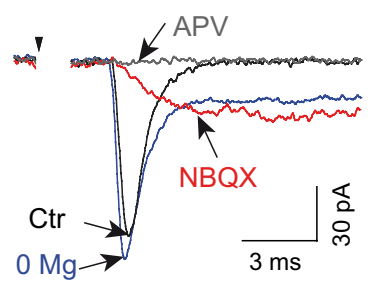

D

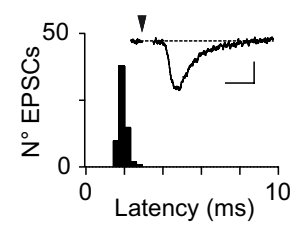

F

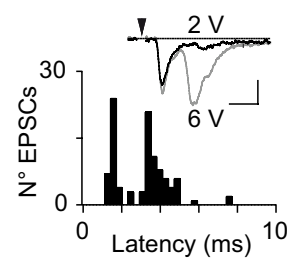

I

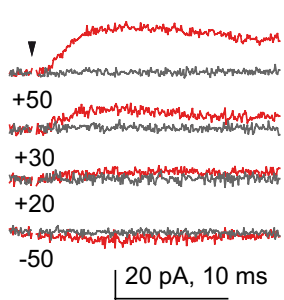

G

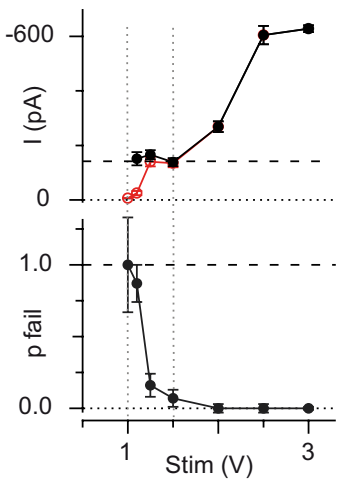

$J$

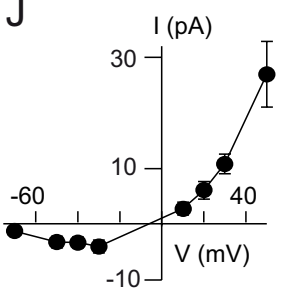

Figure 1. Excitatory mossy fiber and granule cell synaptic inputs evoked in Golgi cells by WM stimulation. $A$, Low-magnification differential interference contrast image of a sagittal cerebellar slice. A patch pipette (rec) contacts a Golgi cell (GoC) in the granular layer (GL) while a stimulation pipette (stim) is immersed in the WM. $\boldsymbol{B}$, Scheme of the afferent excitatory connections to a $\mathrm{GoC}$ activated by WM stimulation. Black cell, Golgi cell; orange fibers, mossy fibers; blue cells, granule cell; dotted line, Purkinje cell layer (PCL); ML, molecular layer. 1 and 2, mf-GoC and GrC-GoC monosynaptic pathways, respectively. 3 and 4, $m f-G r C-G o C$ disynaptic pathways, where a GrC contacts either apical (3) or basolateral (4) GoC dendrites. Pipette "A" stimulates all pathways; pipette "B," at $\geq 300 \mu \mathrm{m}$ from the GoC soma, stimulates pathways 1, 3, and 4. C, EPSCs evoked by WM stimulation (with pipette configuration " $B$ ") at threshold intensity ( $20 \mathrm{~V})$ in a GoC ( $-70 \mathrm{mV}$ ), in the presence of blockers of inhibitory inputs ( 9 consecutive superimposed trials). Latency from stimulus is relatively invariant, suggesting a monosynaptic input from $m f s$. Here (and in all figures), arrowheads indicate stimulus onset; the stimulation artifact is blanked for clarity. $\boldsymbol{D}$, EPSC latency histogram (same cell as in C). There is narrow unimodal distribution (mean latency, $1.9 \mathrm{~ms}$; SD, 0.2 $\mathrm{ms}$ ). Inset, Average of 66 EPSCS. Calibration in D, F insets, $2 \mathrm{~ms}, 25 \mathrm{pA}$. E, Multiple EPSCs in a different cell (same conditions) evoked by threshold ( $2 \mathrm{~V}$; top) and suprathreshold ( $6 \mathrm{~V}$; bottom) stimuli (10 consecutive trials each). The large jitter of late EPSCS suggests a disynaptic input from granule cells. Stronger stimuli preferentially enhance the frequency of long-latency EPSCS. $\boldsymbol{F}$, Latency histogram for all EPSCs at $6 \mathrm{~V}$ (same cell as in $\boldsymbol{E}$ ). Note the multimodal distribution, with an early narrow peak (modal latency, $1.4 \mathrm{~ms}$ ) followed by a second broader peak (median latency, $3.5 \mathrm{~ms}$ ). Inset, Average traces from 50 (black trace; $2 \mathrm{~V}$ ) and 69 (gray trace; $6 \mathrm{~V}$ ) EPSCS. Short- and long-latency EPSCs are present in both averages. G, Mean amplitude (top, red symbols), mean nonfailure amplitude (top, black symbols), and fiber failure probability ( $p_{\text {fail }}$, bottom) of $m f$-EPSCs, plotted versus stimulus intensity, for an exemplar GoC ( $-70 \mathrm{mV}$ ). Inhibitory blockers were omitted. The nonfailure mean is constant between threshold and $1.5 \mathrm{~V}$ (vertical dotted lines), suggesting that in this range a single mossy fiber input was activated. Error bars indicate SEM. $\boldsymbol{H}$, Average $m f$-EPSC $\left(-70 \mathrm{mV}\right.$; threshold stimuli) in control saline (Ctr, black trace), after 15-20 min in $\mathrm{Mg}^{2+}$-free solution (0 Mg; blue trace), and after sequentially adding NBQX (2 $\mu \mathrm{M}$; red trace) and D-APV ( $50 \mu \mathrm{M}$; gray trace). $\mathrm{Mg}^{2+}$ removal uncovers a large, NMDAR-mediated slow current component. Increase of this component in NBQX may result from ongoing $\mathrm{Mg}^{2+}$ removal. $I$, Mean $m f$-EPSCs evoked at threshold in control saline at various holding potentials (from top to bottom: $+50 \mathrm{mV},+30 \mathrm{mV},+20 \mathrm{mV},-50 \mathrm{mV}$ ) in the presence of $2 \mu \mathrm{m} \mathrm{NBQX}, 10 \mu \mathrm{m}$ gabazine, and $500 \mathrm{~nm}$ strychnine, before (red traces) and after (gray traces) adding $100 \mu \mathrm{m} \mathrm{D}-A P V . J, I-V$ relationships for the NMDAR-mediated component of unitary mf-EPSCs, obtained in the presence of NBQX, gabazine, and strychnine. Each point is the average of $7-12$ cells. Error bars indicate SEM.

contribution to feedforward and feedback inhibitory circuits in the GL. EPSCs were recorded from voltage-clamped GoCs at -70 $\mathrm{mV}$ in parasagittal slices, in the presence of gabazine $(10 \mu \mathrm{M})$ and strychnine (500 nM), to exclude a possible contribution of inhibitory synapses (Dumoulin et al., 2001; Hull and Regehr, 2012). Excitatory inputs were activated by extracellular stimulation of the WM at least $300 \mu \mathrm{m}$ from the soma of the recorded GoC (Fig. $1 A$ ), to avoid direct activation of GrC axons (Fig. $1 B$ ). This configuration recruited monosynaptic $m f$ inputs, and $\mathrm{GrC}$ inputs through a disynaptic pathway (see Materials and Methods and Fig. $1 B$ ). It also minimized interference by direct antidromic stimulation of the GoC axon (Dieudonné, 1998), and by GoCGoC electrical coupling, which extends for $\sim 100 \mu \mathrm{m}$ (Dugué et al., 2009).

Threshold stimulation intensity $(1.1-30 \mathrm{~V})$ evoked in most GoCs (21 of 24) an isolated EPSC with short latency and little jitter (Fig. 1C). Latency histograms, obtained from a subset of cells in which a large dataset was available, showed a single narrow peak at $1.5 \pm 0.3 \mathrm{~ms}$, with a dispersion (SD of all latencies) of $0.2 \pm 0.1 \mathrm{~ms}(n=5$ cells; Fig. $1 D)$. In the remaining cells ( 3 of 24 ), stimulation evoked multiple EPSCs (Fig. $1 E$, top traces). The first
EPSC occurred with short invariant latency (mean: $1.4-2.6 \mathrm{~ms}$; SD: $0.1-0.2 \mathrm{~ms}, n=3$ cells), whereas subsequent EPSCs appeared only in a fraction $(25.4 \pm 9.8 \%)$ of the trials and displayed longer and more variable latencies (mean: 3.8-5.7 ms; SD: 0.6-1.7 ms). These late events were not spontaneous EPSCs $\left(p<10^{-4}\right.$; see Materials and Methods) and gave rise to a second synaptic component in the average trace (Fig. $1 F$, inset). An increase in stimulation intensity (by up to 3 times the threshold; $n=20$ cells) raised the frequency of late EPSCs in 65\% of cells (13 of 20, Fig. $1 E$, bottom traces), to $45 \pm 27 \%$ per trial. Latency histograms (from 7 cells) showed a multimodal distribution, with a first narrow peak at $1.6 \pm 0.4 \mathrm{~ms}$ (dispersion: $0.2 \pm 0.1 \mathrm{~ms}$ ), followed by a late hump (median at $4.7 \pm 2.4 \mathrm{~ms}$ ). The two components were separated by $0.6 \pm 0.3 \mathrm{~ms}$ without events (Fig. $1 F, 0.5 \mathrm{~ms}$ in the example). The significantly larger jitter (dispersion: $1.3 \pm 1.2$ $\mathrm{ms}$ ) observed in the late hump (vs first narrow peak, $p=0.015$ ) is consistent with a disynaptic response (Fig. $1 F$ ). In summary, synaptic responses could be separated into monosynaptic shortlatency EPSCs (SL-EPSCs) and disynaptic long-latency EPSCs (LL-EPSCs). Monosynaptic EPSCs most likely arose at the $m f$ GoC input (Fig. 1B, feedforward pathway 1), whereas LL-EPSCs, 
with their longer delay and larger jitter, are likely attributed to the disynaptic $m f$-GrC-GoC input (Fig. $1 B$, feedback pathways 3 and 4).

To investigate the properties of unitary $m f$-EPSCs (Fig. $1 G$ ), we examined the recruitment of $m f s$ during WM stimulation. When gradually increasing stimulus strength above threshold, the failure probability of the SL-EPSC decreased steeply while the mean amplitude increased (Fig. $1 G$ ). The nonfailure mean amplitude remained approximately constant $(p>0.1$, Spearman rank correlation test) for a range of strengths (up to $\sim 3$ times the threshold; $n=12$ cells; Fig. $1 G$ ). This range ("minimal stimulation") therefore likely corresponds to the excitation of a single $m f$, producing a "unitary" EPSC. The unitary events had a fast rise $\left(\mathrm{t}_{20-80}, 0.2 \pm 0.1 \mathrm{~ms}\right)$, and their mean amplitude ranged from 28 to $456 \mathrm{pA}$ (median, $62 \mathrm{pA}$ ). The percentage of failures, when using the largest intensity in the minimal stimulation range (Fig. $1 G$ ), was $26 \pm 20 \%$ (range, $0-62 \%$ ). When using pairs of stimuli at $100 \mathrm{~Hz}$, the paired-pulse amplitude ratio (ratio of mean amplitude of second vs first response) was $1.03 \pm 0.44$ (range, $0.52-$ 2.02). These properties are in agreement with a previous description of $m f$-EPSCs in GoCs (Kanichay and Silver, 2008). Application of the non-NMDA glutamate receptor blocker NBQX $(2 \mu \mathrm{M})$ completely abolished $m f$-EPSCs recorded at -70 $\mathrm{mV}(3.2 \pm 1.6 \%$ of pre-NBQX value, $n=15$ cells $)$, indicating that, at hyperpolarized potentials, $m f$-EPSCs are mediated by non-NMDA glutamate receptors. Removal of $\mathrm{Mg}^{2+}$ at $-70 \mathrm{mV}$ (in the presence of $10 \mu \mathrm{M} \mathrm{D}$-serine) induced the appearance of a slow, NBQX-insensitive and D-APV-sensitive component (peak amplitude, measured in the presence of NBQX, $-34 \pm 41 \mathrm{pA}$; $\mathrm{t}_{20-80}, 5.0 \pm 3.1 \mathrm{~ms} ; n=9$ cells; Fig. $\left.1 H\right)$. In control conditions (in the presence of $\mathrm{Mg}^{2+}$ and NBQX), the amplitude of the D-APV-sensitive component was $27 \pm 6 \mathrm{pA}$ at $+50 \mathrm{mV}(n=12$ cells) and $-4 \pm 1 \mathrm{pA}$ at $-30 \mathrm{mV}(n=7$ cells; Fig. $1 I)$. These NMDAR-mediated currents displayed a current-to-voltage relation typical of GluN2A/2B-containing receptors (Fig. 1J). Our results thus demonstrate the presence of active NMDA receptors at $m f$-GoC postsynaptic sites.

\section{GrC- and $m f$-EPSCs contribute equivalent charge contents to GoC excitation during repetitive $m f$ activity}

It is well known that the excitation of GrCs by $m f$ inputs may require the temporal summation of multiple synaptic inputs during low-frequency asynchronous activity (Schwartz et al., 2012) or during high-frequency trains (D’Angelo et al., 1995). To evaluate the relative contribution of $m f$ and $\mathrm{GrC}$ inputs to GoC excitation during physiological activity, we applied trains of WM stimulations at $100 \mathrm{~Hz}$ (5-20 stimuli; repeated at 0.1 $\mathrm{Hz}$ ). In control conditions (without inhibition blockers), the number of LL-EPSCs increased significantly with stimulation number within the train $(p=0.0002$; one-way ANOVA; Fig. $2 A, C)$.

To confirm that disynaptic LL-EPSCs originated from GrC-GoC inputs, we monitored the frequency of LL-EPSCs during pharmacological manipulations of $\mathrm{GrC}$ synaptic drive. GrCs undergo inhibitory control by tonic $\mathrm{GABA}_{\mathrm{A}}$ conductances (Hamann et al., 2002) and by phasic inhibitory synaptic inputs resulting from the spontaneous and evoked discharge of GoCs (Forti et al., 2006; Dugué et al., 2009). Antagonism of inhibitory synaptic currents will thus augment GrC firing upon $m f$ stimulation and preferentially increase the activation of the disynaptic $m f$-GrC-GoC pathway. Accordingly, the frequency of LL-EPSCs after the fifth stimulus in gabazine/ strychnine was $256 \pm 62 \%(p=0.016)$ of its value before addition of the antagonists, whereas the frequency of SLEPSCs was unchanged $(105 \pm 10 \% ; p>0.9 ; n=7$ cells; Fig. $2 C)$. The jitter of LL-EPSCs increased during the train, as shown by the slow rise (latency to peak of the LL-EPSC, $3.9 \pm$ $0.3 \mathrm{~ms}$ at second stimulus; $4.6 \pm 0.3 \mathrm{~ms}$ at fifth stimulus; $p<$ $0.05, n=7$ cells) and prolonged duration of the long-latency component in the averaged trace (Fig. 2A), consistent with synaptic summation in GrCs.

In GrCs, the temporal summation of $m f$ inputs critically depends upon NMDAR activity (D'Angelo et al., 1995; Schwartz et al., 2012). Correspondingly, in GoCs, bath application of the NMDAR blocker D-APV (50 or $100 \mu \mathrm{M}$ ) reduced LL-EPSC frequency after the fifth stimulus by $80 \pm 7 \%(p<0.005, n=9$ cells; Fig. $2 B, D)$. In contrast, the frequency of SL-EPSCs was nearly constant during the train ( $p=0.46$, one-way ANOVA) and was not significantly affected by D-APV (SL-EPSC frequency after the fifth stimulus in D-APV: $94 \pm 9 \%$ of pre-D-APV value, $p=0.50$, $n=9$; Fig. $2 B, D)$. The opposite effects of D-APV and gabazine/ strychnine on the frequency of LL-EPSCs confirm that these events arise from activity at GrC-GoC synapses. Thus, in the rest of this study, LL-EPSCs will be identified with GrC-EPSCs and SL-EPSCs with $m f$-EPSCs.

The selective sensitivity of the disynaptic GrC relay to the NMDA antagonist D-APV was used to evaluate the relative contributions of $m f$ and GrC inputs to the excitatory drive of GoCs during repetitive WM activation with variable stimulation strength. We first measured the total charge transfer to GoCs, provided jointly by $m f$ - and GrC-EPSCs, during trains of stimulation in the $\operatorname{WM}(6,10$, or 20 stimuli at $100 \mathrm{~Hz})$. For these experiments, gabazine and strychnine were added to avoid a potential contamination by evoked inhibitory conductances. We then measured the charge transfer, provided mostly by $m f$-EPSCs, after addition of D-APV $(50-100 \mu \mathrm{M})$ (Fig. $2 B$ ). Calculating the difference in the synaptic charge before and after application of D-APV provided a lower estimate of the disynaptic charge transfer produced by GrCs in the absence of inhibition. The relation between disynaptic and monosynaptic charges (Fig. $2 E ; 8$ cells) displays a significant linear correlation $\left(R^{2}=0.94, p<10^{-4}\right)$ with a slope of $1.83 \pm$ 0.17 . Because inhibition would approximately halve the number of disynaptic GrC inputs to GoCs (as assessed at the end of a train of 5 stimuli at $100 \mathrm{~Hz}$; Fig. 2C) (Schwartz et al., 2012), we conclude that GoCs receive a similar amount of charge from $m f$ inputs and disynaptic $\mathrm{GrC}$ inputs during repetitive activation in physiological conditions.

\section{Ultrastructural identification of $\mathrm{GrC}$ ascending axon contacts onto GoCs in the GL}

In the previous experiments (Figs. 1 and 2), the parasagittal orientation of the slice ensured that GrCs contributing disynaptic inputs are to be located in the same parasagittal volume as the recorded GoC. These local granule cells account for approximately half of the excitatory synaptic drive to GoCs during repetitive $m f$ activation. The existence of en passant synapses formed by local $\mathrm{GrC}$ ascending axons onto basolateral and/or apical GoC dendrites was proposed in early morphological studies (Mugnaini et al., 1974; Palay and ChanPalay, 1974) but remains to be confirmed. These proximal contacts could constitute a privileged synaptic connection between local GrCs and GoCs and therefore a potent inhibitory feedback circuit in the GL.

To selectively examine the morphology of contacts formed on GoCs in the GL, we unambiguously identified GoC dendrites in 
A

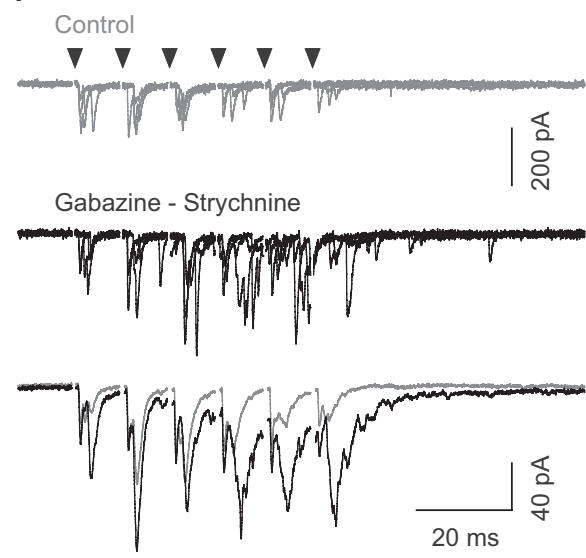

C
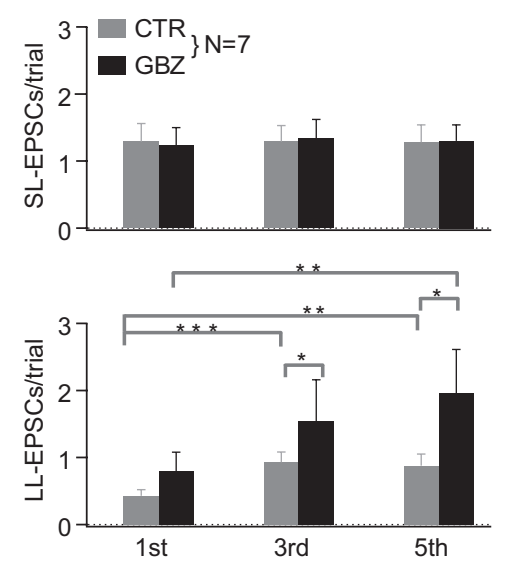

B
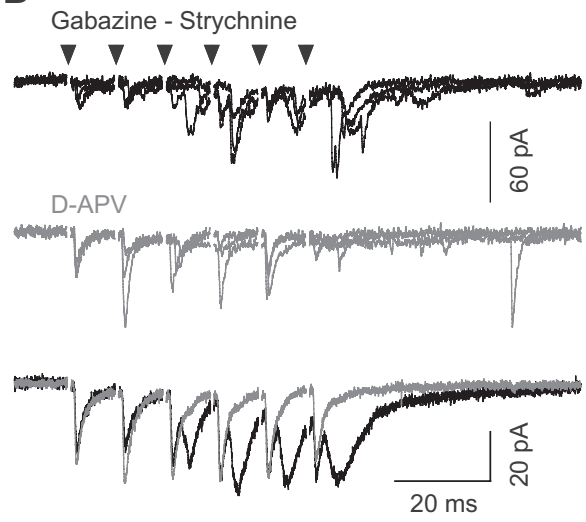

D

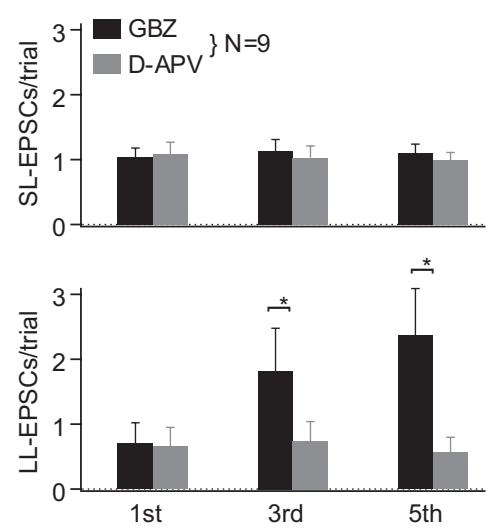

$\mathrm{E}$

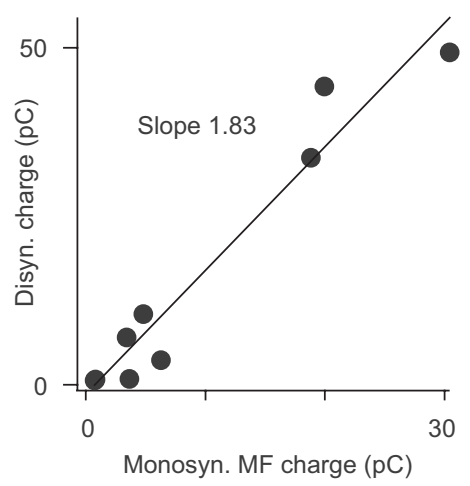

Figure 2. GABA $\mathrm{R}$ - and NMDAR-sensitive recruitment of disynaptic granule cell inputs during train stimulation. Whole-cell recording of EPSCs from GoCs at $-70 \mathrm{mV}$ during WM train stimulation ( 6 stimuli at $100 \mathrm{~Hz}$, delivered every 10 s). Traces are aligned at time of the stimulus (arrowheads). $A$, Five superimposed consecutive traces showing EPSCs recorded in GoC in control saline (top) and after bath application of gabazine and strychnine (middle). Bottom, Averages (35 consecutive trials) from the same experiment (gray trace, control; black trace, inhibitory blockers present). The blockers produce a strong increase in the number of long-latency EPSCS. $\boldsymbol{B}$, In another cell, EPSCs before (top) and after D-APV application (middle; 5 consecutive trials in each row), in the presence of gabazine and strychnine. Bottom, Average of 44 consecutive responses from the same cell before (black trace) and after (gray trace) D-APV. D-APV strongly and selectively reduces long-latency EPSCS. C, Summary plot of the effects of GABA receptor block on the frequency of short-latency (SL; top) and long-latency (LL; bottom) EPSCs. Bars represent the averaged frequency ( \pm SEM) over 7 cells, before (CTR; gray bars) and after (GBZ; black bars) perfusion of $10 \mu \mathrm{m}$ gabazine and $500 \mathrm{~nm}$ strychnine. Frequency (events/trial) is measured over $10 \mathrm{~ms}$ after the first (1st), third (3rd), and fifth (5th) stimulus. The LL-EPSC frequency increases significantly with stimulus number (in (TR and GBZ), and with application of gabazine/strychnine (at the third and fifth stimulus). ${ }^{*}, p<0.05$; ${ }^{* *}, p<0.005 ; * * *, p<0.0005$. SL-EPSCs are not affected in all cases. In a few cells, two distinct SL-EPSCS were present (as judged from their short, nonjittery latency), explaining the $>1$ value of mean SL-EPSC frequencies. D, Summary of the effects of NMDA receptor block on the frequency of SL- (top) and LL-EPSCs (bottom). Averaged frequency ( \pm SEM) over 9 cells in gabazine/strychnine (GBZ; black bars) and after addition of 50 or $100 \mu \mathrm{m}$ D-APV for at least $3 \mathrm{~min}$ (D-APV; gray bars). The increase of LL-EPSC frequency with stimulus number is abolished by D-APV. SL-EPSCS are not affected. ${ }^{*}, p<0.05$. E, The relationship between the charge transfer resulting from disynaptic LL-EPSCs and monosynaptic SL-EPSCs, evoked by trains of $6-20$ stimuli at $100 \mathrm{~Hz}$ in 8 cells, in the presence of inhibitory blockers. The monosynaptic charge is measured as the time integral of the average current along the train after bath perfusion of D-APV (artifacts blanked); the disynaptic charge is the difference between total and monosynaptic charge. Black line indicates linear regression; slope, $1.83 \pm 0.17$.

electron micrographs by performing pre-embedding immunostaining against neurogranin, a $\mathrm{Ca}^{2+}$ binding protein specific of GoCs in the cerebellar cortex, or against GFP in a transgenic mouse model expressing GFP in glycinergic interneurons (GlyT2-EGFP mice; see Materials and Methods). Immunopositive dendrites, generally of large diameter (Fig. $3 A-D$ ), were occasionally found inside glomeruli, where they were contacted by $m f$ profiles (Fig. $3 A-C$ ). In several cases, excitatory synaptic contacts were found between those two elements, as judged from the presence of synaptic vesicles close to the presynaptic membrane and of a thick postsynaptic density. In some cases, more than one morphological contact site was found inside the same glomerulus, putatively on the same GoC dendrite (Fig. $3 A, C$ ). Overall, this EM analysis confirms the existence of glomerular $m f$ contacts with $\mathrm{GoC}$ dendrites, including putative multiple contacts made by one rosette to a single dendrite.
Another type of synaptic contact was also found on GoC in the GL (Fig. $3 D, E$ ). In several cases, bundles of thin axons running in the GL were found to contact thick postsynaptic densities of basolateral GoC dendrites (Fig. 3D) or GoC somata (Fig. 3E). Each synaptic articulation was composed of a simple en passant bouton occurring outside glomeruli and containing a small number of vesicles, a typical $\mathrm{GrC}$ axon feature. In contrast, climbing fiber (CF), unipolar brush cell, or $m f$ terminals contain high numbers of densely packed vesicles (Palay and Chan-Palay, 1974). The presence of bundles of axons excludes CF thin collaterals and clearly identifies $\mathrm{GrC}$ ascending axons. Thus, in contradiction with the general belief that functional $\mathrm{GrC}-\mathrm{GoC}$ connections are formed exclusively by $p f s$ on apical GoC dendrites (Dieudonné, 1998; Bureau et al., 2000; Misra et al., 2000; Brickley et al., 2003; Watanabe and Nakanishi, 2003; Beierlein et al., 2007; Kanichay and Silver, 2008; Menuz et al., 2008; Robberechts et al., 2010), our 

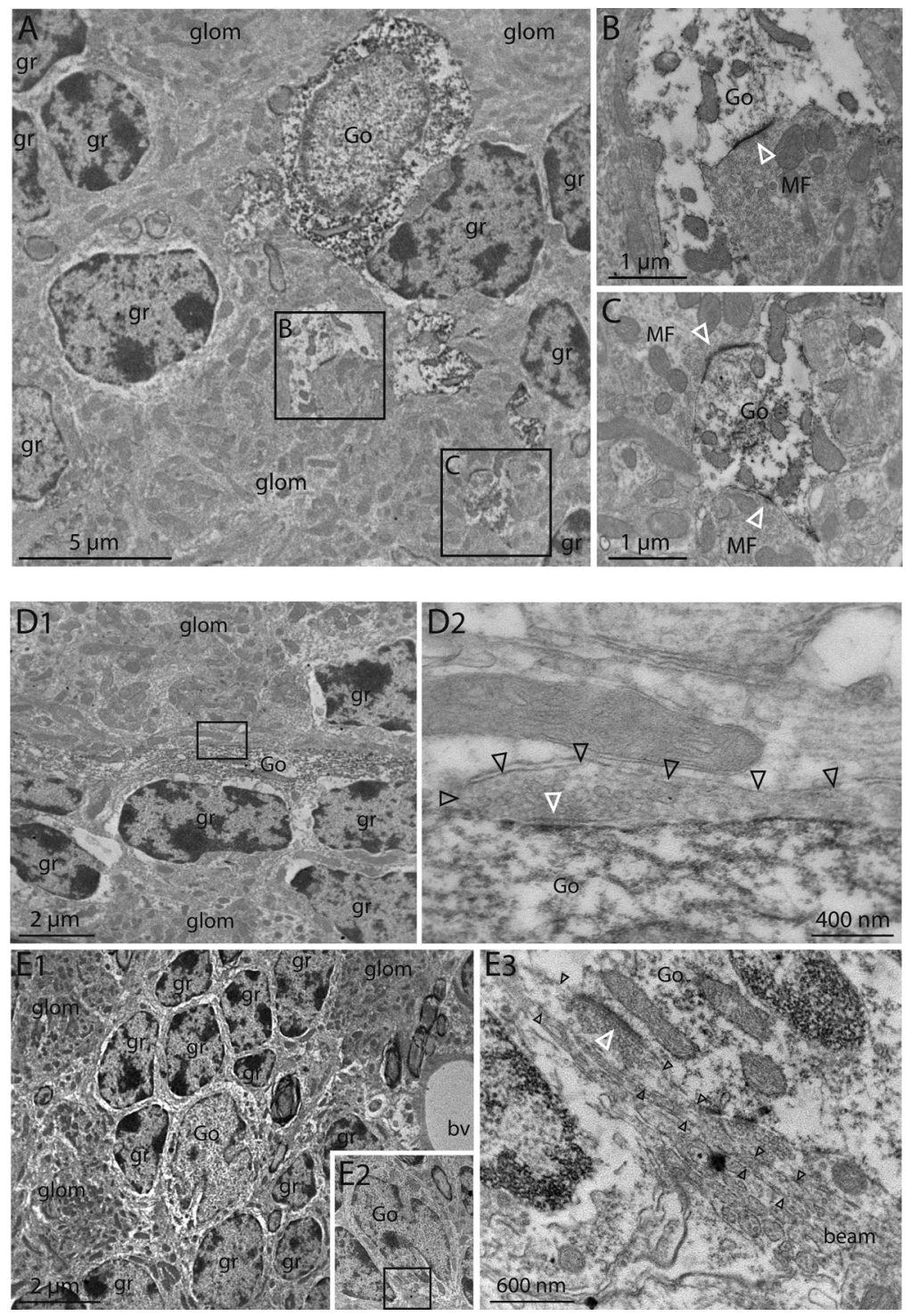

Figure 3. Excitatory contacts onto Golgi cells in the GL identified with electron microscopy. Analysis of ultrathin cuts of GlyT2GFP mice cerebella stained with an anti-GFP antibody amplified with the peroxidasic system to identify Golgi cells. $\boldsymbol{A}$, A peroxidasestained $\mathrm{GoC}_{\mathrm{C}}$ dendrite (boxed regions $B$ and $\mathrm{C}$ ) penetrates a glomerulus ( $\mathrm{glom}$ ), well differentiated from surrounding $\mathrm{Gr} C$ somata $(\mathrm{gr})$, in the proximity of a $\mathrm{G}_{0}(\mathrm{soma}(\mathrm{Go}) . \boldsymbol{B}, \boldsymbol{C}$, Intraglomerular articulations formed by the dendrites boxed in $\boldsymbol{A}$ shown at higher magnification. $G_{0} C$ dendrites (Go) receive asymmetric synapses from a mossy fiber terminal (MF) at both locations. There are numerous and densely packed vesicles in mossy fiber terminals. Note the postsynaptic densities on Golgi cell dendrites (white arrowheads). D1, Low-magnification view of a stained $\mathrm{GoC}$ dendrite running in the $\mathrm{GL}$ in between $\mathrm{GrC}$ bodies and outside of a nearby glomerulus. D2, Enlargement of the region boxed in D1, showing that the $\mathrm{G}_{0} \mathrm{C}$ dendrite is separated from the glomerulus by two fibers, running parallel to each other. One of these fibers (black arrowheads), putatively a GrC ascending axon, forms an asymmetric synaptic contact with the $\mathrm{G}_{0}$ C dendrite (white arrowhead). E1, Low-magnification view of a GoC body surrounded by granule cell bodies (gr) in the GL. E2, Serial sections were acquired, and a low resolution image of another section is shown. E3, Magnification of the boxed region in E2 showing an a bundle ("beam") running outside of glomeruli and forming asymmetric synapses with the GoC body. Black arrowheads indicate an individual fiber; white arrowhead indicates the corresponding postsynaptic density.

results now establish the existence of synapses formed by $\mathrm{GrC}$ ascending axons on GoC dendrites in the GL.

\section{$\mathrm{Ca}^{2+}$ imaging reveals functional $\mathrm{GrC}$ ascending axon synapses in the GL}

To determine the functional contribution of GrCs ascending axon synapses in the GL to the disynaptic activity evoked by WM stimulations, we combined ultrafast 2-photon $\mathrm{Ca}^{2+}$ imaging and patchclamp recording of GoCs. Juxta-threshold WM stimulations were applied in a $\mathrm{Mg}^{2+}$-free extracellular medium complemented with $10 \mu \mathrm{M}$ D-serine, which potentiates NMDA currents. These conditions maximize the frequency of disynaptic GrC-EPSCs in lowintensity stimulation conditions (Fig. 1) (Schwartz et al., 2012) and increase postsynaptic $\mathrm{Ca}^{2+}$ influx. Individual GoCs were clamped at subthreshold potential and filled through the pipette with the high-affinity $\mathrm{Ca}^{2+}$-sensitive dye Fluo-4 $(100 \mu \mathrm{M})$ and the morphological dye Alexa-594 (Fig. 4A,F). We then scanned systematically the basolateral dendrites in the GL in search of fluorescence transients correlated with the stimulation. In the majority of cells, we could identify at least one area of the dendrites with transients correlated in time with the stimulation. The fluorescence signal of this area was then acquired at submillisecond sampling intervals, quasi-simultaneously from a small number (15-25) of closely spaced $(\sim 1 \mu \mathrm{m})$ POIs covering the nearby dendrites (Fig. 4A,F). To identify the precise location of the active synaptic contacts, the latency and rise time of the fluorescence transients averaged over all trials were compared between POIs (see Materials and Methods). A " $\mathrm{Ca}^{2+}$ entry site" was defined as a POI where the latency from stimulus was smaller, and the kinetics of rise was faster, than in flanking POIs (Fig. $4 B, G$ ).

We detected 16 entry sites on basolateral dendrites $(20-80 \%$ rise time, $10.8 \pm 5.3 \mathrm{~ms}$; rise time in flanking POIs, $28 \pm 12.3 \mathrm{~ms}, p<$ 0.002). In 10 of these sites, from 6 cells, the latency of the mean fluorescence change matched the latency of the electrophysiological mean $m f$-EPSC $\left(\mathrm{Ca}^{2+}\right.$ transient latency, $2.3 \pm 0.6 \mathrm{~ms} ; m f$-EPSC latency, $1.5 \pm 0.6$ $\mathrm{ms}$; delay from the onset of the $m f$-EPSC, $0.9 \pm 0.2 \mathrm{~ms}$; Fig. 4C). Latencies, measured from the largest individual responses at each site, had a small variability (SD of the 10 largest responses, $1.8 \pm 1.1 \mathrm{~ms}, n=10$ sites; Fig. $4 D, E)$. Moreover, $m f$-EPSC failures were in all cases accompanied by a $\mathrm{Ca}^{2+}$ transient failure (data not shown, see Materials and Methods), confirming that fluorescence responses at short-latency entry sites corresponded to activation of $m f-G o C$ synaptic contacts.

In the remaining 6 entry sites (from 3 cells), $\mathrm{Ca}^{2+}$ rise occurred after long, variable latencies from WM stimulation ("long-latency entry sites"), consistent with influx evoked by disynaptic GrC-EPSCs. Figure $4 F-J$ illustrates the behavior of one of these sites, where the latency of the mean response was $5.6 \mathrm{~ms}$, with a delay of $4.6 \mathrm{~ms}$ from the onset of the mean SL-EPSC (i.e., the $m f$-EPSC; Fig. $4 H$ ), and latencies measured in individual trials varied largely (between $3.9 \mathrm{~ms}$ and 26.8 ms; Fig. 4I). The electrophysiological responses showed both $m f$ and GrC-EPSCs, but no fluorescence signal was detected at short 


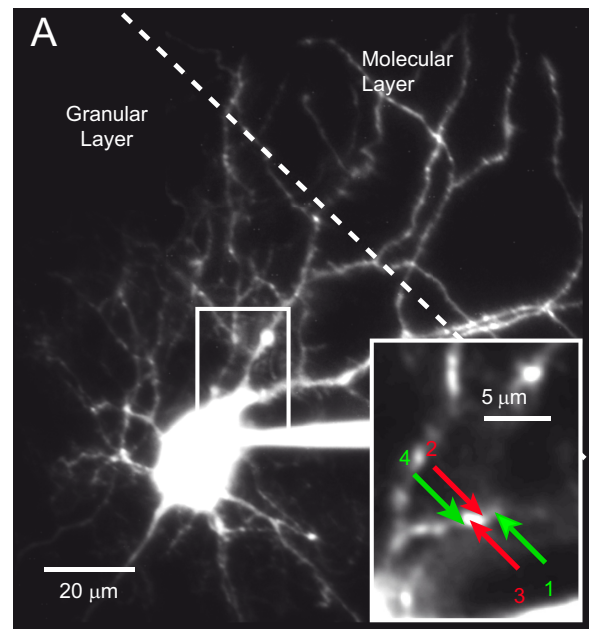

B
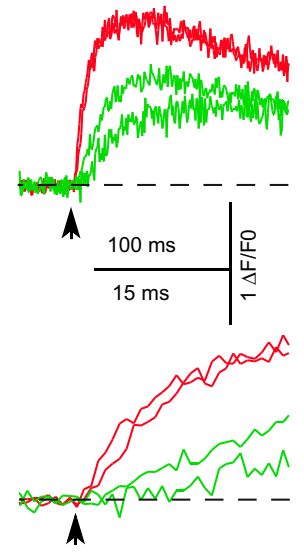

C

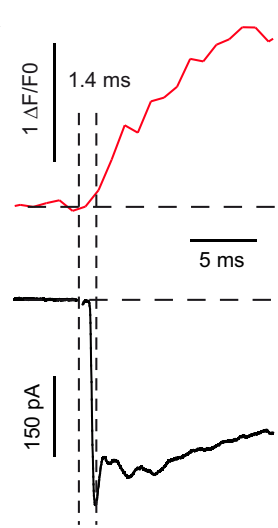

D
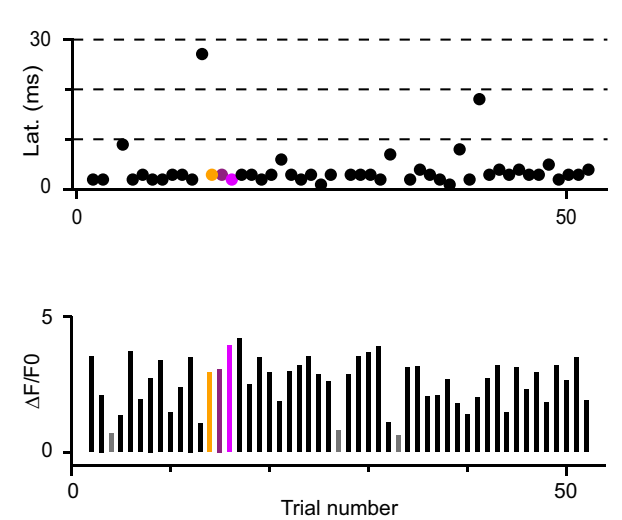

$E$

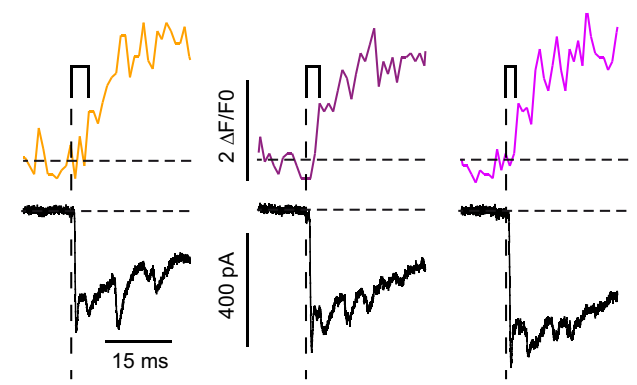

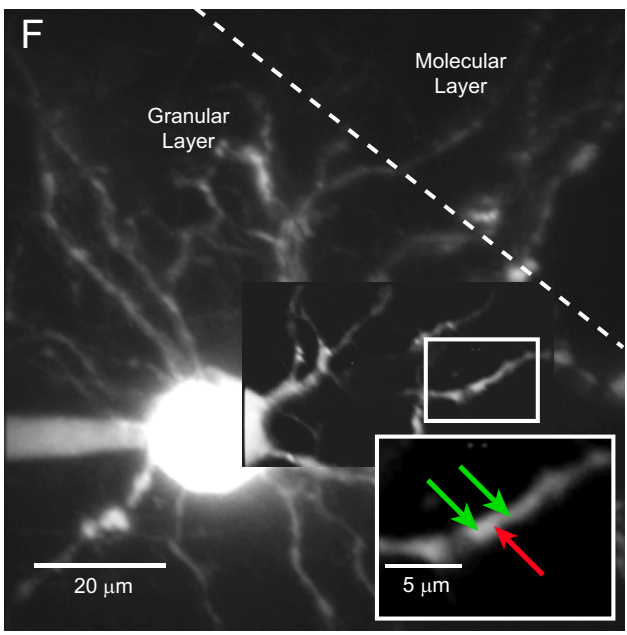

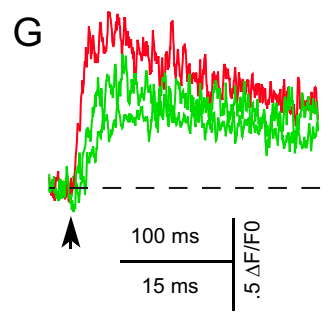

$\mathrm{H}$

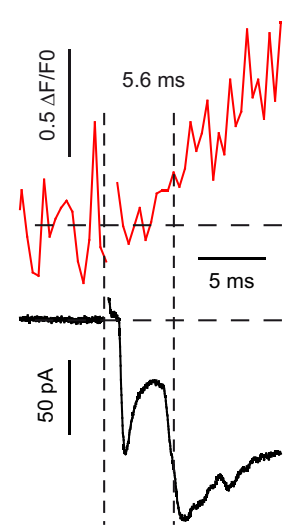

I
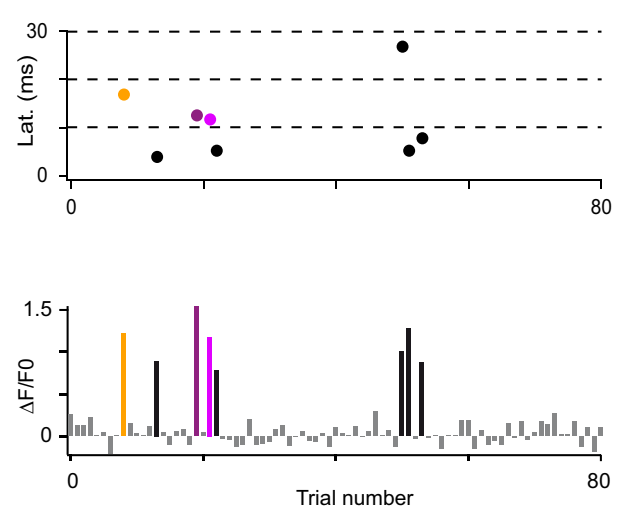

$\mathrm{J}$

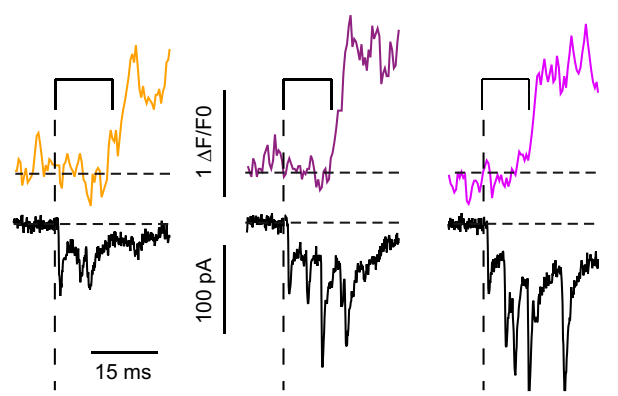

Figure 4. Ultrafast 2-photon imaging of postsynaptic $\mathrm{Ca}^{2+}$ influx at $\mathrm{mf}$ - and GrC-Golgi contacts in the GL. Analysis of $\mathrm{Ca}^{2+}$ fluorescence transients in the basolateral dendrites of two different $\mathrm{GoCs}(\boldsymbol{A}-\boldsymbol{E}$ and $\boldsymbol{F}-\boldsymbol{J})$ during WM stimulation in $\mathrm{Mg}^{2+}$-free saline. Fluorescence multiphoton images were obtained from the dendrites of cells filled with Alexa-594 and (Figure legend continues.) 
latency (Fig. $4 J$ ). In a total of 6 sites, the latency of the mean $\mathrm{Ca}^{2+}$ transient varied between 5.6 and $8 \mathrm{~ms}$, with a delay from the mean $m f$-EPSC rise between 3.9 and $6.4 \mathrm{~ms}$. The latencies measured in individual trials were highly variable (SD of the 10 largest responses at each site, $12.7 \pm 10.1 \mathrm{~ms}, n=5$ ), in contrast with the small variability observed at short-latency entry sites $(p<0.01)$. Furthermore, the probability of observing a detectable response at longlatency entry sites was very low in 4 of 5 sites examined (between $10 \%$ and $37 \%$; mean, $24 \pm 13 \%$; Fig. $4 I$ ), as expected from a disynaptic relay ( $m f-\mathrm{GrC}-\mathrm{GoC})$. At the fifth site, the probability of response was $93 \%$.

The amplitude of fluorescence transients at entry sites was quantified as the average $\Delta \mathrm{F} / \mathrm{F}_{0}$ over $7 \mathrm{~ms}$ after rise $\left(\Delta \mathrm{F}_{7 \mathrm{~ms}}\right.$; see Materials and Methods). At short-latency entry sites $(n=10), \Delta \mathrm{F}_{7 \mathrm{~ms}}$ of the mean response was $0.55 \pm 0.27$ (range, $0.25-1.01$ ), or $0.7 \pm 0.29$ (range, 0.34-1.16) when averaging nonfailure responses only. At long-latency entry sites, $\Delta \mathrm{F}_{7 \mathrm{~ms}}$ of nonfailure responses was $0.36 \pm$ 0.19 (range, $0.10-0.56 ; n=6$ ), significantly smaller $(p=0.04$ ) than at short-latency sites. This may be explained by the larger jitter of long-latency responses and/or by genuinely smaller $\mathrm{Ca}^{2+}$ rise. To distinguish between these possibilities, $\Delta \mathrm{F}_{7 \mathrm{~ms}}$ was measured individually in the 10 largest responses in short- and long-latency entry sites, yielding significantly larger mean values in the first group (1.46 \pm $0.67, n=10$, vs $0.61 \pm 0.22, n=5 ; p=0.027)$. These results suggest that postsynaptic $\mathrm{Ca}^{2+}$ influx in basolateral GoC dendrites is larger at contacts made by $m f s$ than at en passant contacts made by GrCs, at least when NMDA currents are potentiated.

$\Delta \mathrm{F}_{7 \mathrm{~ms}}$ at short-latency entry sites was sensitive to block of NMDARs. Application of $50 \mu \mathrm{M}$ D-APV reduced $\Delta \mathrm{F}_{7 \mathrm{~ms}}$ by $81.4 \pm$ $11 \%$ (range, $72-100 \% ; n=7$ sites in 4 cells, $p<0.01$ ), suggesting that $\mathrm{Ca}^{2+}$ influx at $m f$-GoC contacts mainly occurs through NMDA receptors. In parallel, as expected (Fig. 2), D-APV practically eliminated disynaptic EPSCs (data not shown).

\footnotetext{
$\leftarrow$

(Figure legend continued.) Fluo-4 through the recording pipette. $A, F$, Projected fluorescence images of two Golgi cells, extending apical dendrites toward the ML and basolateral dendrites in the $\mathrm{GL}$. The proximal portion of an ascending $\mathrm{GoC}$ dendrite (white rectangle) is magnified (bottom right rectangle). Arrows indicate analyzed points of interest (POIs). B, G, Top graphs, Mean fluorescence transients, from corresponding color-coded POls in $\boldsymbol{A}$ and $\boldsymbol{F}$; averages of 50 $(\boldsymbol{B})$ and $8(\boldsymbol{G})$ stimuli. Black arrows indicate stimulation time. POls marked in red indicate responses with shorter delay from stimulus and faster rise than flanking POls marked in green, as better shown in the bottom graphs (expanded traces), indicating that these POls are the sites of synaptic $\mathrm{Ca}^{2+}$ entry. Traces from sites marked 2 and 3 in $\boldsymbol{A}$ are nearly superimposed in $\boldsymbol{B}$, implying the presence of an entry site between the two POls. $C, H$, Average EPSC (bottom black trace) $(n=50$ in $\boldsymbol{C} ; n=80$ in $\boldsymbol{H})$ and the corresponding fluorescence transient (top red trace; same as in $\boldsymbol{B}, \boldsymbol{G}$ ) from the $\mathrm{Ca}^{2+}$ entry sites marked by red arrows in $\boldsymbol{A}, \boldsymbol{F}$. Vertical dotted lines indicate stimulation time (left line) and time of the first detected point in the fluorescence response (right line; see Materials and Methods). Numbers indicate latency (in ms). The evoked EPSC has a fast component ( $m f$-EPSC), which peaks and decays in 2-3 ms, followed by a second slower component (the compound disynaptic GrC EPSC). The fluorescence signal in C rises around the time of the $m f$-EPSC peak, whereas the signal in $\boldsymbol{H}$ rises during the slow rising phase of the GrC-EPSC. D, $\boldsymbol{I}$, Top graphs, Latency of fluorescence responses versus trial number for the $\mathrm{Ca}^{2+}$ entry sites in $\boldsymbol{A}$ and $\boldsymbol{F}$. Bottom graphs, Fluorescence change $\left(\Delta \mathrm{F} / \mathrm{F}_{0}\right)$ relative to the prestimulus baseline, averaged over $150 \mathrm{~ms}$ after stimulation, versus trial number, for the same sites. Gray bars represent detection failures. Colored dots (top) and bars (bottom) indicate trials described in $\boldsymbol{E}$ and $\boldsymbol{J}$. In $\boldsymbol{D}$, latencies show very small jitter; a few values exceed $5 \mathrm{~ms}$, possibly representing failures of the local $m f-G_{0} C$ input in the presence of late $\mathrm{Ca}^{2+}$ diffusion from a nearby activated site. I I I, most trials are classified as failures (in gray), except for a few detected responses with long and variable latencies. $\boldsymbol{E}, \boldsymbol{J}$, Fluorescence transients (top traces) and the corresponding EPSCS (bottom traces) in individual trials from the sites in $\boldsymbol{D}$ and $\boldsymbol{I}$, respectively. Brackets over the fluorescence traces indicate poststimulus delay before signal detection. $\boldsymbol{E}$, The fluorescence response starts around the time of the $m f$-EPSC peak. J, The fluorescence response occurs in correspondence of disynaptic EPSCs, long after the mf-EPSC has decayed.
}

These data established the presence of functional en passant synapses formed by GrC ascending axons ("aa synapses") in the GL. We have thus established that local excitation onto basolateral GoC dendrites arises from two types of contacts that may play functionally distinct roles in the modular regulation of GoC activity.

\section{D-immunohistochemical quantification of ascending axon contacts onto GoCs in the GL}

The presence of a synapses onto GoCs constitutes a substrate for a specific feedback circuit onto local GrCs. Assessing the number of $a$ a contacts to GoCs is crucial to evaluate the functional impact of this circuit. To this end, we performed an immunohistochemical identification of $a a$ varicosities followed by quantitative 3D confocal microscopy. Glutamatergic neurons express at least one of three vesicular transporters, vGluT1-3, which are accumulated presynaptically at synaptic contacts (Takamori, 2006). In the cerebellar cortex, each of the three glutamatergic elements ( $m f s$, GrCs, and CFs) has a specific phenotype. GrCs express exclusively vGluT1, whereas CFs express vGluT2 only (Fremeau et al., 2001; Hioki et al., 2003). Mossy fibers, depending on their nuclei of origin, can express vGluT1 alone, vGluT2 alone, or both transporters (Fremeau et al., 2001; Hisano et al., 2002; Varoqui et al., 2002; Hioki et al., 2003; Gebre et al., 2012). However, because of the modular organization of the cerebellar cortex, some regions are completely devoid of $m f s$ expressing only vGluT1 (Gebre et al., 2012). In these regions, GrC varicosities can be identified unambiguously as the only profile positive for vGluT1 but negative for vGluT2 (vGluT1-only phenotype).

We performed triple immunostaining against vGluT1, vGluT2, and GFP in GlyT2-EGFP animals, which express GFP in $\sim 85 \%$ of the GoCs. We found that the upper part of the GL was sprinkled with vGluT1-only puncta similar to $p f$ varicosities in the ML and located outside of the glomeruli (Fig. $5 B, C$, arrows). In regions innervated by vGluT2-expressing $m f s$, these puncta were the sole vGluT1-only profiles in the GL (Fig. 5A-C). vGluT1-only puncta, which shall be called $a a$ varicosities, were much less abundant in the lower half of the GL, as expected from the lower density of ascending axons (and of GoC dendrites which they may contact). A striking feature of $a a$ varicosity localization seemed to be their close apposition to GoC neurites stained with GFP (Fig. $5 B, C$ ). To quantify this aspect, vGluT1only puncta were automatically detected in high-resolution 3D confocal stacks (see Materials and Methods; Fig. 5D,E), and the surfaces of GFP-positive neurites were segmented (Fig. $5 E$ ). The ML was systematically excluded from analysis. In the GL, $85 \%$ of a a varicosities were located at $<1 \mu \mathrm{m}$ (center to surface) from a GFP-positive neurite (Fig. $5 E, F$ ), with a mode of the distribution of $0.4 \mu \mathrm{m}$ (Fig. $5 F$; 1488 varicosities in 6 confocal stacks from 2 animals; total volume $188 \times 10^{3} \mu \mathrm{m}^{3}$ ). Only $15 \%$ of the varicosities were located at $>1 \mu \mathrm{m}$, in the tail of the distribution. However, this represents an underestimate of the varicosities that are not in synaptic contact with a GFP-positive neurite, as short distance measurements may result from fortuitous proximity of a varicosity to a dendrite. Therefore, we computed the distribution of a "random distance," obtained by rotating the GFP channel relative to the vGluT 1 channel by $180^{\circ}$. In this random histogram, $51 \%$ of the varicosities are located at $>1 \mu \mathrm{m}$ from GFP neurites. Hence, assuming that all distances $>1 \mu \mathrm{m}$ in the original data represent varicosities not in synaptic contact, a scaling factor of $\sim 0.3(15 \%$ over $51 \%)$ is needed to fit the tail of the random distance distribution to the original distribution, indicating that a maximum of $30 \%$ of the varicosities in the original histogram may be located randomly relative to the GFP-positive dendrites 

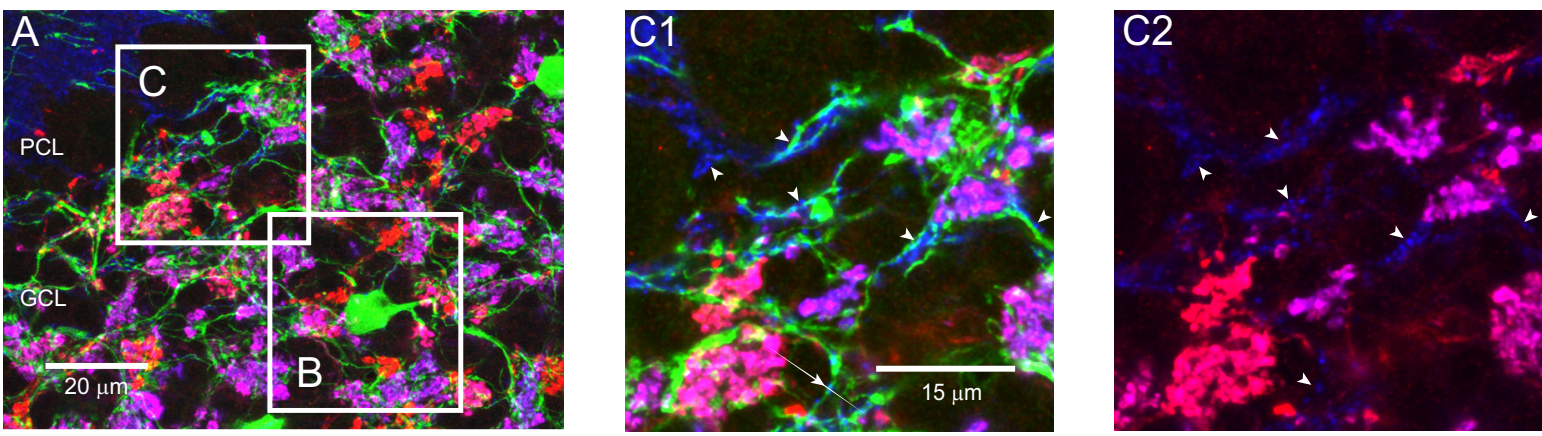

GlyT2-EGFP vGlüT1 vGlüT2
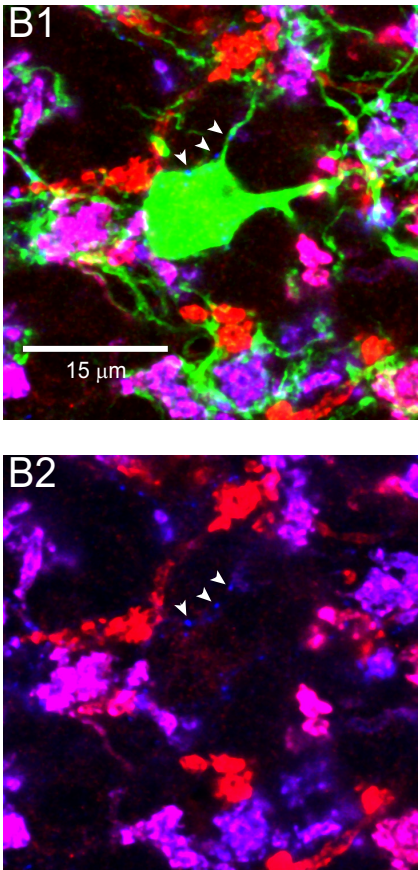

D

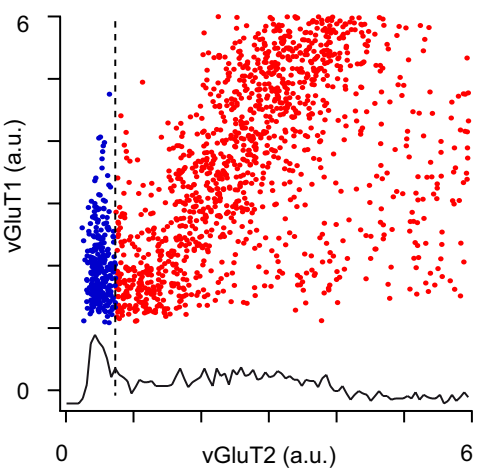

F

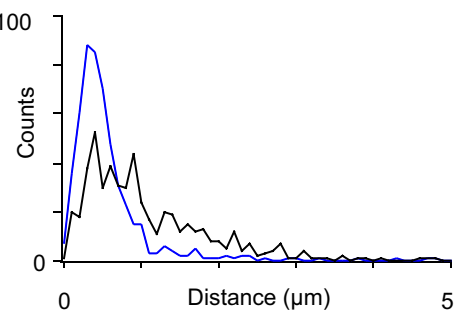

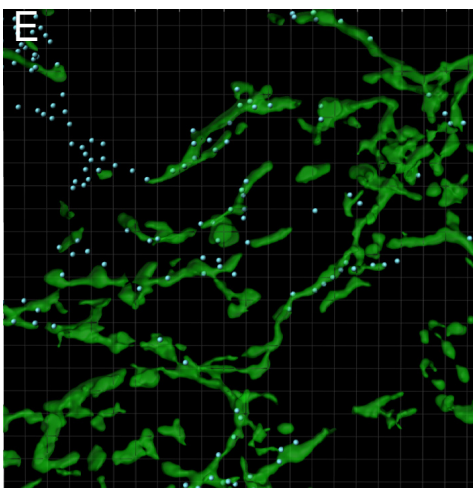

G

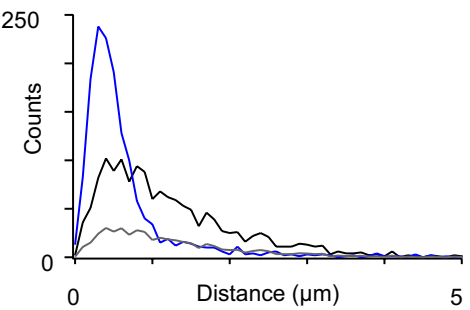

Figure 5. Immunolocalization of granule cell ascending axon contacts with Golgi cells in the GL. Glutamatergic varicosities identified by immunostaining of the vesicular glutamate transporters v GluT1 (blue channel) and vGluT2 (red channel) in parasagittal sections obtained from GlyT2-EGFP mice (green channel: Golgi cell somata and processes). A, Large field of view ( $92 \times 123 \mu \mathrm{m}$, projection depth $2.38 \mu \mathrm{m}$ ) showing the general organization of terminals in the cerebellar cortex. The $\mathrm{GL}$ is occupied by large mossy fiber rosettes displaying various ratios of vGluT1 and vGluT2 staining. There is absence of vGluT1-only rosettes in this region. vGluT1-only parallel fiber boutons are seen in the molecular layer (top left) togetherwith rarevGluT2-only climbing fiber terminals. B1, B2, Enlargement of the region B, boxed in $A$, showing small vGluT1-only varicose profiles in the GL and their apposition to the cell body and dendrites of a GFP-positive GoC (projection depth $1.36 \mu \mathrm{m}$ ). vGluT1-only profiles most likely correspond to the boutons of $\mathrm{GrC}$ a in the GL. In B2, the GFP channel was removed for better display of vGluT1-only profiles, which show weaker staining than the large mf rosettes. C1, C2, Same as B1, B2 for the region C (projection depth $1.36 \mu \mathrm{m}$ ), illustrating the dense innervation of the GFP-positive $\mathrm{GOC}_{\mathrm{C}}$ neurites by vGluT1-only varicosities in the upper part of the GL. $\boldsymbol{D}$, Relative intensity of vGluT1 and vGluT2 staining in punctuate profiles detected in the blue channel (vGluT1) in region C, both in mossy fiber rosettes and outside glomeruli. The vGluT2 intensity histogram (black curve) is bimodal, with a first population (nonglomerular puncta) showing background levels of immunoreactivity (vGluT1-only, blue dots). In contrast, glomerular puncta (red points) display fixed ratios of vGluT1 and vGluT2 staining, as evidenced by the linear correlation in their distribution. $\boldsymbol{E}$, VGluT1-only puncta are displayed as blue dots on top of segmented GFP-positive GoC neurites, for the region displayed in C; distance of blue dots from the nearest GoC neurite is shown in $\boldsymbol{F}$. By comparison with $\mathbf{C}$, all selected puncta in the $\mathrm{GL}$ are indeed extraglomerular. $\boldsymbol{F}$, Blue curve represents the distribution of the distance of vGluT1-only puncta from the surface of $\mathrm{Go}(\mathrm{C}$ dendrites in the $\mathrm{GL}$ of the stack shown in $A$. Black curve represents randomized distance distribution obtained by rotating the GFP channel by $180^{\circ}$. G, Distance distribution (in blue) and randomized distance distribution (in black) for all the regions analyzed ( 6 confocal stacks, 2 animals). Gray curve represents the scaled randomized distance histogram accounting for the randomly located puncta in the blue distribution (see Results). The difference between the gray and blue curves is an estimate of the number of vGluT1-only puncta truly apposed to GFP-positive GoCs.

(Fig. 5G, scaled gray histogram). This may correspond to contacts made with GFP-negative GoCs (15\% of Golgi cells) (Simat et al., 2007), to intracellular vGluT1 staining outside of synaptic varicosities or to contacts with other cell types.

We have previously shown that $\sim 1000$ GoCs are found in the GL volume underlying $1 \mathrm{~mm}^{2}$ of Purkinje cell layer (Dugué et al., 2009). Here, the projected area explored during immunohistochemical quantification was $2480 \mu \mathrm{m}^{2}$, corresponding to $\sim 2.5 \mathrm{GoCs}$. A total of 1489 vGluT1-only puncta were counted, $\sim 1000$ of which were nonrandomly apposed to GoC dendrites. Hence, the number of morphological aa contacts can be estimated at $\sim 400$ per GoC. This number represents a lower estimate, as the contacts made by a $a$ in the lower GL or in the ML were not considered.

\section{Fast kinetics of basolateral $m f$ synaptic inputs recorded at the soma}

We sought a strategy to evaluate the relative contribution of $a a$ contacts onto basolateral dendrites to the total excitatory inputs received by GoCs. The passive properties of the thin apical dendrites of GoCs have been shown to exert significant low-pass filtering on synaptic currents recorded at the soma (Kanichay and Silver, 2008; Vervaeke et al., 2012). We reasoned that the decay 
kinetics of $\mathrm{GrC}$ ascending axon EPSCs arising in basolateral GoC dendrites should be faster than that of $p f$-EPSCs, which arise in apical dendrites, and similar to that of $m f$-EPSCs.

We started with the examination of $m f$-EPSCs kinetics in a large experimental series using juxta-threshold WM stimulations $(n=55)$. The mean amplitude (72 pA; median value across cells), the percentage of failures $(23 \pm 19 \%)$, and the $20-80 \%$ rise time $(0.2 \pm 0.1 \mathrm{~ms})$ of $m f$-EPSCs in this series were similar to the corresponding values in the minimal stimulation series $(p=$ $0.87, p=0.54$, and $p=0.82$, respectively; Fig. $1 G)$, consistent with the stimulation of unitary $m f$-EPSCs. The decay of the average $m f$-EPSCs was in most cases (43 of 48 cells examined) well fitted by a double exponential (see Materials and Methods; Fig. $6 A)$. The slower decay time constant, which accounted for $19 \pm$ $14 \%$ of the total amplitude and for $54 \pm 16 \%$ of the total charge $(154 \pm 148 \mathrm{fC}$; median $125 \mathrm{fC})$, was highly variable $\left(\tau_{\text {slow }}=4.9 \pm\right.$ $3.0 \mathrm{~ms}$, range, $1.6-13.2 \mathrm{~ms}$ ). The slow EPSC component was generally not observed in isolation (absent in 32 of 48 cells; $<5 \%$ of the failures in the remaining 16 cells), in accordance with results of Kanichay and Silver (2008). This contrasts with the case at $m f$-GrC synapses, where the frequently observed isolated slow component was attributed to glutamate spillover from nearby $m f$-GrC contacts (DiGregorio et al., 2002).

The fast decay time constant $\left(\tau_{\text {fast }}\right)$ of $m f$-EPSCs in connections displaying a biexponential decay was $0.6 \pm 0.2 \mathrm{~ms}$ (range, 0.3-1.2 ms; $n=43$ ), similar to the time constant in connections with a monoexponential decay $\left(\tau_{\text {fast }}=0.6 \pm 0.1\right.$, range, $0.5-0.8$ ms; $n=5$ ) (Fig. $6 A$ ). The $20-80 \%$ rise time (averaged from measurements in individual trials, to avoid the impact of release jitter) varied from 0.1 to $0.5 \mathrm{~ms}(0.2 \pm 0.1 \mathrm{~ms}, n=48$ cells $)$ and was positively correlated to the time constant of fast decay $(p<$ $0.001 ; n=43$ biexponentially decaying EPSCs) (Fig. 6B). In addition, the amplitude of the fast decay component was inversely correlated to its time constant $(p<0.01$; Fig. $6 C)$. These data indicate that the kinetics of $m f$-EPSCs are minimally filtered by basolateral GoC dendrites (filtering $\tau_{\text {fast }}$ to an upper limit of 1.2 ms, 42 of 43 connections).

\section{Slow kinetics of $p f$-EPSCs arising in apical dendrites: characterization through postsynaptic $\mathrm{Ca}^{2+}$ imaging in the molecular layer}

Electrical activation of $p f$ bundles in the ML often generates spillover transmission characterized by the slow time course of the postsynaptic current (Marcaggi et al., 2003). Therefore, to assess properly the distance-dependent filtering of EPSCs in apical dendrites, we analyzed the kinetics of $p f$-EPSCs evoked by juxtathreshold electrical stimulations in the ML. Because such stimulations can evoke back-propagating action potentials in GrC ascending axons, resulting in $a a$-EPSCs in the GL, we used $\mathrm{Ca}^{2+}$ imaging to identify true $p f$-EPSCs. GoCs were filled with morphological and $\mathrm{Ca}^{2+}$ dyes, and the stimulation pipette was placed at the surface of the parasagittal brain slice above a deeprunning GoC apical dendrite, favoring $p f$ inputs and preventing direct electrical stimulation of the dendrite (Fig. 6D; see Materials and Methods). Evoked $\mathrm{Ca}^{2+}$ transients were imaged simultaneously at POIs regularly spaced over a stretch of the apical dendrites, around the presumed $p f$ input site (Fig. 6D). In many cases, threshold stimulations evoked fast-decaying EPSCs that were not associated with $\mathrm{Ca}^{2+}$ transients in the underlying dendrites, suggesting the involvement of backfired aa synapses. In 6 cases, which were analyzed in further detail, juxta-threshold stimulations evoked fast $\mathrm{Ca}^{2+}$ influx at a single dendritic entry site (Fig. 6D, entry sites detected as in Fig. $4 B, G$ or inputs to GL).
Postsynaptic $p f-\mathrm{Ca}^{2+}$ transients displayed a latency of $1.4 \pm 0.4$ ms from stimulation onset $(n=6)$, similar to the latency of AMPA EPSCs $(1.0 \pm 0.1 \mathrm{~ms} ; n=6)$. The total fluorescence signal, summed over all the responding points, rose with an exponential time constant of $3.5 \pm 0.7 \mathrm{~ms}(n=5)$ (Fig. $6 D)$, similar to the time course of the integral of the AMPA EPSCs $(2.5 \pm 0.7 \mathrm{~ms}, n=$ $5)$. As $\mathrm{Ca}^{2+}$ transients were recorded at hyperpolarized potentials in the presence of $1 \mathrm{~mm}$ external $\mathrm{Mg}^{2+}$, conditions in which NMDA receptors and voltage-gated $\mathrm{Ca}^{2+}$ channels are blocked, our data suggest that $\mathrm{Ca}^{2+}$-permeable AMPA receptors (AMPARs) constitute a major source of $\mathrm{Ca}^{2+}$ influx at $p f$ synapses onto GoCs.

The analysis of the $p f$-EPSCs kinetics was complicated by the finding that, in half of the cases (3 of 6), both small-amplitude slow EPSCs and large-amplitude fast EPSCs were evoked (Fig. $6 E)$. In those cases, "fast" and "slow" EPSCs were separated according to their charge transfer during the first millisecond (Fig. $6 E$, legend). $\mathrm{Ca}^{2+}$ influx occurred in most trials, whether slow EPSCs or both types of EPSCs were evoked (Fig. 6F). However, the peak amplitude of the $\mathrm{Ca}^{2+}$ influx (see Materials and Methods) was only correlated to the charge of slow EPSCs but not to the charge of the fast EPSCs (Fig. 6G). We conclude that fast EPSCs do not arise at the site of $\mathrm{Ca}^{2+}$ imaging but most likely at a contact formed on more proximal dendrites by a back-fired $\mathrm{GrC}$ ascending axon. Indeed, the latency of the fast EPSCs, measured at $20 \%$ of the peak, was always longer (by $0.1 \pm 0.01 \mathrm{~ms}$; $n=3)$ than the latency of slow EPSCs. Moreover, the amplitude $(178.7 \pm 57 \mathrm{pA})$ and decay time constant $(1.0 \pm 0.25 \mathrm{~ms} ; n=3$; Fig. $6 H$ ) of fast EPSCs were reminiscent of proximal inputs (Fig. $6 A-C)$. Slow $p f$-EPSCs were averaged over the trials at which fast EPSCs did not occur and their decay was fitted by a double exponential function (Fig. $6 H$ ), yielding a first time constant of $2.7 \pm$ $0.6 \mathrm{~ms}$ (range, $1.3-3.8 \mathrm{~ms} ; n=6$ ).

To quantify the dependence of EPSC decay kinetics on dendritic filtering, the distance from the GoC soma to the imaged $p f$ entry sites was measured on 3D morphological stacks (minimum $91 \mu \mathrm{m}$; maximum $210 \mu \mathrm{m}$ ). The relationship between EPSC decay time constant and distance to the soma is shown in Fig. $6 I$ for the apical GrC-GoC entry sites (red symbols) and for the basolateral $m f$-GoC entry sites detected with GL imaging and WM stimulation (experiments of Fig. 4, black symbols). The decay time constant was always faster for sites on the basolateral dendrites $(0.7 \pm 0.2 \mathrm{~ms}$, range, $0.3-1.0 \mathrm{~ms} ; n=6 ; p<0.01)$, with a significant linear correlation with the somatic distance of slope $12.8 \pm 2.7 \mathrm{~ms} / \mathrm{mm}(p<0.01)$. These data show that $p f$-EPSCs arising in apical dendrites can be separated from EPSCs arising in the basolateral dendrites, like $m f$-EPSCs, based on their decay kinetics. In the following section, we assume that EPSCs with a decay time constant faster than $1.2 \mathrm{~ms}$ arise from basolateral dendrites (because $98 \%$ of $m f$-EPSCs, but none of the $p f$-EPSCs, measured in the lower ML have a decay time constant $<1.2 \mathrm{~ms}$ ).

\section{Ascending axon contacts contribute half of the excitatory synaptic drive provided to GoCs by local GrCs}

Having set a kinetic criterion for EPSCs occurring in basolateral dendrites, we analyzed the contribution of aa synapses to the synaptic drive of GoCs by local GrCs. We first performed patchclamp recordings from pairs of synaptically coupled GrCs and GoCs. GrCs located within a few tens of micrometers from the GoC body were stimulated to threshold in the loose-cell attached configuration, while recording the GrC juxtacellular spikeinduced current (Barbour and Isope, 2000) (see Materials and Methods; Fig. $7 A-C$ ). In 8 pairs, GrC spikes evoked EPSCs in 
A Mossy fibre EPSCs

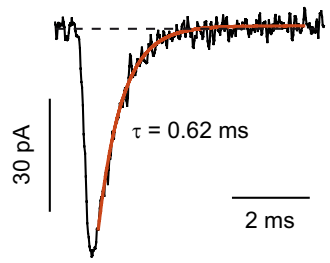

B

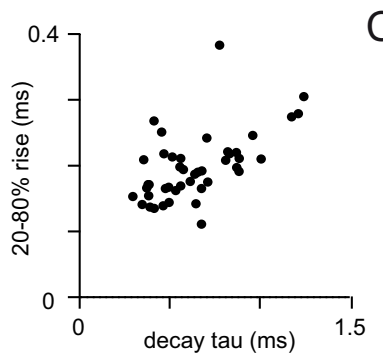

C

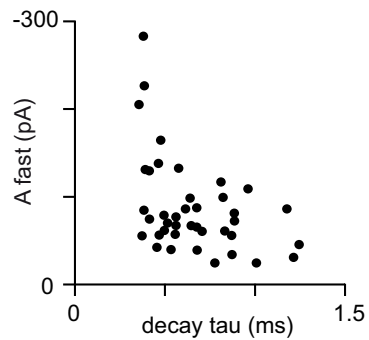

D
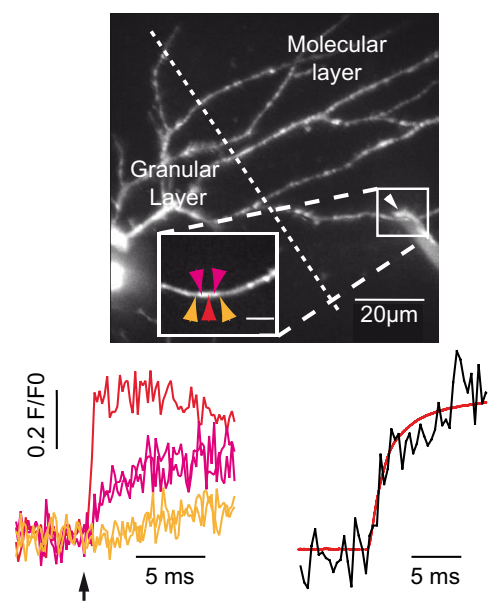

G

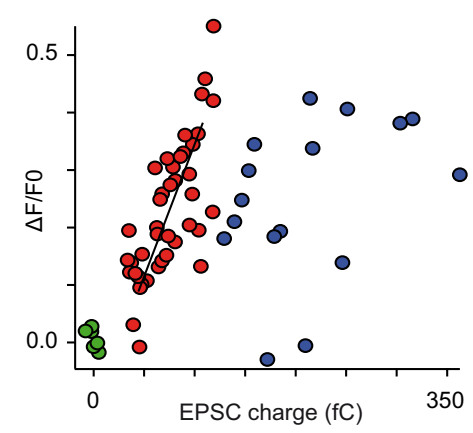

E
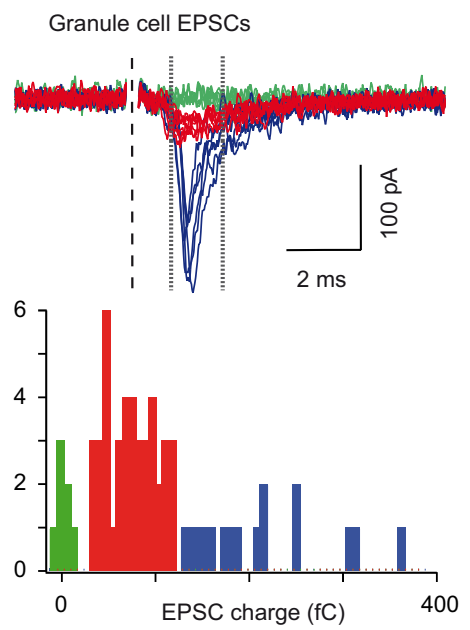

$\mathrm{H}$

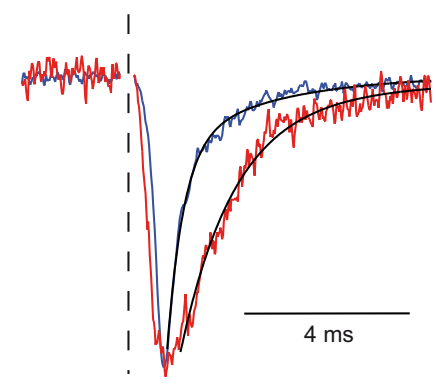

F

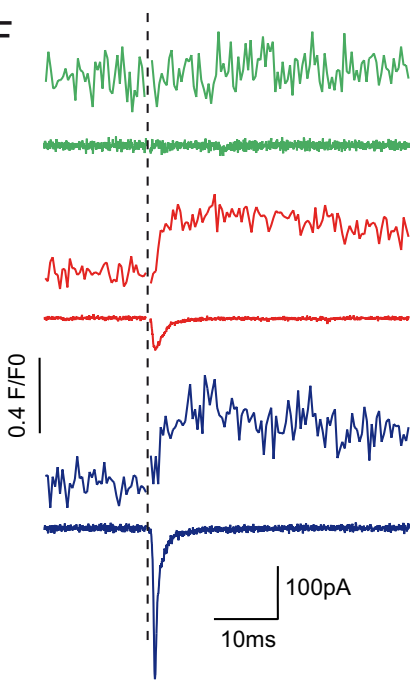

I

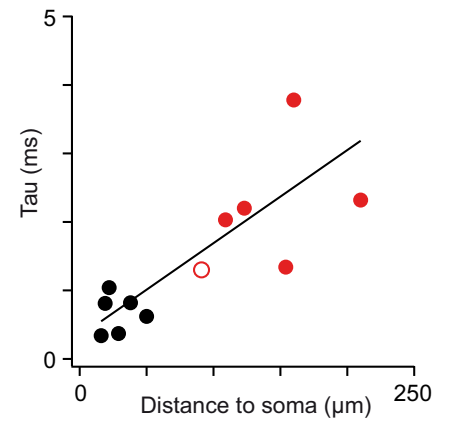

Figure 6. The decay kinetics of $m f$-EPSCS and GrC-EPSCS, and the relationship between EPSC decay time and synapse distance from the GoC soma. A, Unitary $m f$-EPSCs evoked by minimal WM stimulation, from two different cells. Black traces represent individual trials. Red traces represent best fits with decaying exponentials. Left, Monoexponentially decaying EPSC (average of 50 trials). Right, Biexponentially decaying EPSC ( $A_{\text {slow }} / A_{\text {fast }}=0.19$; average of 20 trials). Most ( 43 of 48 ) cells displayed biexponential $m f$-EPSC decay. $B, 20-80 \%$ rise time of unitary $\mathrm{mf}$-EPSCS versus the respective fast decay time constant, for 43 biexponentially decaying cells. Rise and decay are positively correlated $(r=0.55, p<0.001, \mathrm{Spearman}$ rank correlation). $\boldsymbol{C}$, In the same cells, amplitude of the unitary $m f$-EPSC fast component $\left(A_{\text {fast }}\right)$ versus the respective time constant $\left(\tau_{\text {fast }}\right) . A_{\text {fast }}$ and $\tau_{\text {fast }}$ are negatively correlated $(r=$ $-0.41, p<0.01)$. D, Projected morphology of a GoC obtained by multiphoton imaging of Alexa-594 introduced through the recording pipette in a parasagittal slice. Apical dendrites ascending to the molecular layer cross the Purkinje cell layer (dotted line indicates the apex of Purkinje cells). A stimulation electrode (white arrowhead) was placed at the ML surface above a deep-running dendrite (boxed region, inset). $\mathrm{Ca}^{2+}$ influx was imaged quasi-simultaneously at POls indicated by colored arrows in the inset. Lower left panel, The corresponding fluorescence traces are displayed (color coded; average of 65 stimulations). Black arrow under the traces represent stimulation time. Lower right, Sum of the fluorescence signal over all responding points (black trace), representing the total $\mathrm{Ca}^{2+}$ influx. The charge integral of the average AMPA EPSC (red trace) is superimposed on the fluorescence $\mathrm{Ca}^{2+}$ transient. There is similarity in their rise kinetics. $\boldsymbol{E}$, Top, Electrophysiological traces with evoked EPSCs. Bottom, Histogram of EPSC charges (measured between the two vertical lines in the top traces). Three types of responses can be discriminated based on the magnitude of the charge integral: failures ( $0-15 \mathrm{fC}$; green traces; $n=7)$, low amplitude slow events (15-120 fC; red traces; $n=42)$, and large amplitude fast events ( $>120 \mathrm{fc}$; blue traces; $n=16)$. $F$, Average $\mathrm{Ca}^{2+}$ transients (top traces; averaged for 5 POls around the entry site) and corresponding EPSCs (bottom traces) for the three types of responses in $E$. G, Correlation between the EPSC charge (measured between the dotted lines of $E$ ) and the $\mathrm{Ca}^{2+}$ influx $\left(\Delta F / F_{0}\right)$ recorded in the apical dendrite underlying the stimulation electrode. $\Delta F / F_{0}$ here is the average over $1.45 \mathrm{~ms}$ around the peak for the sum of all responding POls. The charge of $s m a l l$ EPSCs is significantly correlated to $\mathrm{Ca}^{2+}$ influx (red points and black line; Pearson's correlation coefficient $0.793 ; p<0.001 ; n=42$ ), indicating a synaptic contact at the imaging site. Large EPSCs are not correlated with $\mathrm{Ca}^{2+}$ influx (blue points; Pearson's correlation coefficient $0.371 ; p>0.1 ; n=16$ ), indicating that large EPSCs do not occur at the $\mathrm{Ca}^{2+}$ imaging site but may crown smaller EPSCS occurring at this site, which are responsible for the $\mathrm{Ca}^{2+}$ influx. $\boldsymbol{H}$, Peak-scaled averaged EPSCs showing that the local pf events (red) decay with slower kinetics than the distal aa events (blue). Black lines indicate biexponential fits to the decay phase (blue EPSC, first component: $0.6 \mathrm{~ms}$; red EPSC, first component: $1.3 \mathrm{~ms}$ ). I, First decay time constant of $p f$-EPSCs ( $n=6$; red symbols) and $m f$-EPSCS ( $n=6$; black symbols) as a function of the distance of the synaptic site (identified by $\mathrm{Ca}^{2+}$ imaging) from the soma. The hollow red circle represents the experiment illustrated in this figure $(\boldsymbol{D}-\boldsymbol{H})$. 

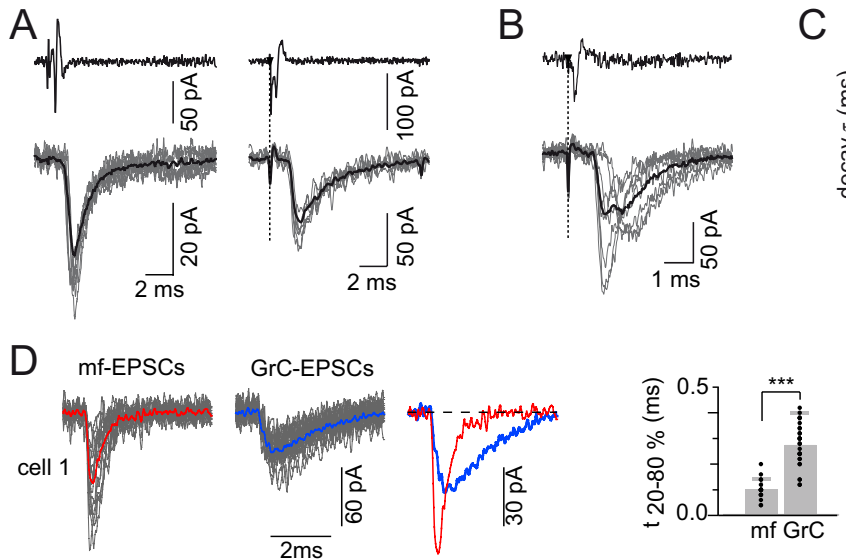

E
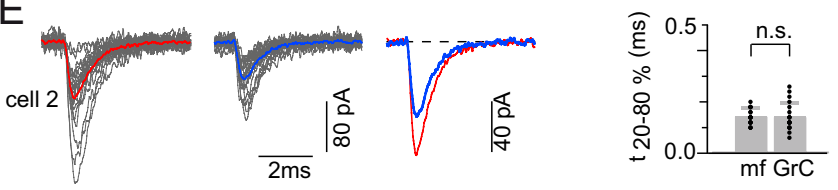

Figure 7. Similar numbers of GrC-EPSCS with fast and slow kinetics revealed by granule-Golgi paired recordings and extracellular stimulation recordings. $A$, Exemplar recordings from two different $\mathrm{GrC}-\mathrm{GOC}$ pairs, illustrating fast (left) and slow (right) EPSC kinetics. Top, Loose-cell attached recordings of juxtacellular spike-induced current in two GrCs. Bottom, Simultaneous EPSCs (gray traces) and their averages (black traces) recorded in postsynaptic GoCs clamped at $-70 \mathrm{mV}$. Decay time constant: $0.7 \mathrm{~ms}$ (bottom left) and $1.8 \mathrm{~ms}$ (bottom right). $\boldsymbol{B}$, In another pair, presynaptic GrC spikes (top) evoke two distinct EPSC responses with different latencies. Bottom, Superimposed individual responses (gray traces) and their average (black trace). C, Scatter plot of the mean EPSC decay time constant versus latency from presynaptic spike in 8 paired recordings. Red lines connect measurements for 2 distinct EPSCS obtained in single pairs. The dashed line indicates the linear regression through all points (see Results). D, E, Kinetic properties of $m f$ - and GrC-EPSCs evoked by extracellular WM stimulation in two exemplar GoCs ( $\boldsymbol{D}$, cell $1 ; \boldsymbol{E}$, cell 2). Traces: individual EPSCS (in gray) and their averages (in color) aligned at the time of $20 \%$ of rise. Left column: mf-EPSCS. Middle column: GrC-EPSCS. Averages are superimposed in the right column. Right, Summary plots of the $20-80 \%$ rise time $\left(\mathrm{t}_{20-80}\right)$ and weighted decay time $\left(\tau_{w i}\right.$;see Materials and Methods) of all $m f$ - and GrC-EPSCs in cell 1 (D) and cell 2 (E). Gray bars indicate mean \pm SD; dots, individual values. In cell 1 , kinetic parameters indicate much slower GrC- than mf-EPSCs ( $\mathrm{t}_{20-80}, 0.3 \pm 0.1 \mathrm{vs} 0.1 \pm 0.04 \mathrm{~ms} ; \tau_{\mathrm{w}}, 1.6 \pm 0.4$ vs $0.3 \pm 0.1 \mathrm{~ms}$ ), whereas in cell 2 the two inputs are similarly fast ( $\mathrm{t}_{20-80}, 0.1 \pm 0.05 \mathrm{vs} 0.1 \pm 0.03 \mathrm{~ms} ; \tau_{\mathrm{w}}, 0.6 \pm 0.1 \mathrm{vs} 0.6 \pm$ $0.2 \mathrm{~ms}){ }^{* * *}, p<0.0005 ;$ n.s., not significant.

voltage-clamped GoCs, at $-70 \mathrm{mV}$, with a mean amplitude of $-45 \pm 27 \mathrm{pA}$ (range, -10 to $-77 \mathrm{pA}$ ) and mean charge transfer of $55 \pm 38 \mathrm{fC}$ (range, 5-121 fC). The paired-pulse amplitude ratio of $1.46 \pm 0.82$ (range, $0.26-2.96$ ) was similar, in average and variability, to that of the $m f$ inputs. The decay phase could be fitted by a single exponential, consistent with the nonglomerular nature of the GrC-GoC synaptic contacts. Both the latency of the evoked EPSCs, $1.3 \pm 0.3 \mathrm{~ms}$ (range, $0.8-1.9 \mathrm{~ms}$ ), their $20-80 \%$ rise time, $0.3 \pm 0.1 \mathrm{~ms}$ (range, $0.2-0.6 \mathrm{~ms}$ ), and their decay time constants, $1.3 \pm 0.4 \mathrm{~ms}$ (range, $0.5-2.1 \mathrm{~ms}$ ), were extremely variable. The decay time constant of the GrC-EPSCs was linearly correlated to the latency from the presynaptic $\mathrm{GrC}$ spike, with a slope of $1.22 \pm 0.32\left(R^{2}=0.615, p=0.023\right.$; Fig. $\left.7 C\right)$. In 2 cell pairs, the synaptic response consisted of doublets of EPSCs (Fig. $7 B$ ), both with mean latency differences of $0.6 \mathrm{~ms}$. As expected, rise and decay times were longer for the longer-latency EPSC (Fig. $7 C)$. This correlation is consistent with the fact that synapses formed further along the ascending axon, hence activated with larger delay, will impinge on more distal dendrites of the GoC, generating more filtered somatic EPSCs (Fig. 6). In contrast, propagation along the $p f$ should increase the delay, but should only marginally increase filtering, because consecutive synapses are formed at approximately the same distance from the soma. Given the distance dependence of dendritic filtering (Fig. 6I), the latency-decay relation in paired $\mathrm{GrC}-\mathrm{GoC}$ recordings (Fig. $7 \mathrm{C}$ ) can be converted into a latency-distance relation, providing an
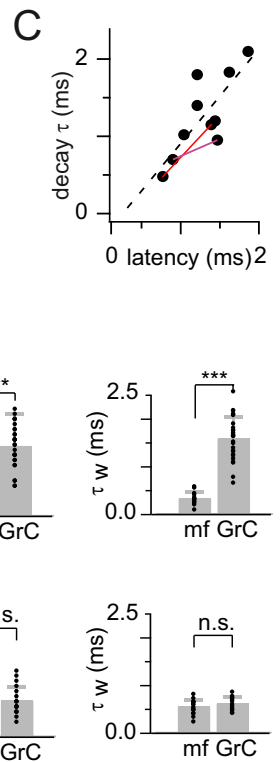

estimate of propagation speed of $\sim 100$ $\mu \mathrm{m} / \mathrm{ms}$, close to the value for $\mathrm{GrC}$ axon conduction speed (Eccles et al., 1967; Gardner-Medwin, 1972; Llinas, 1982). Overall, these data are consistent with the proposal that most contacts between GoC and local GrCs are made by aa. The fastestdecaying GrC-EPSCs were as fast as the fast component of proximal $m f$-EPSCs (Fig. $6 A-C)$, compatible with an origin at juxtasomatic sites. Furthermore, the decay time constant of $60 \%$ of the EPSCs ( 6 of 10 connections) was faster than $1.2 \mathrm{~ms}$, indicating that more than half of the local GrC synapses are made by the $a a$ axon on basolateral GoC dendrites. The other synapses may be formed by distal aa contacts or by $p f$ contacts on GoC apical dendrites in the ML.

To quantify the contribution of $a a$ synapses in the GL to the excitation of GoCs during evoked synaptic activity, we also compared the rise and decay kinetics of disynaptic, long-latency GrCEPSCs and short-latency $m f$-EPSCs in WM minimal stimulation experiments. Recordings were obtained in the absence of D-APV and in the presence of inhibitory blockers, to maximize the occurrence of GrC-EPSCs. The mean nonfailure amplitude of GrC-EPSCs was 47 pA (median across cells; range, 20-92 pA), corresponding to a charge transfer of $76 \mathrm{fC}$ (median; range, 31-172 fC), similar to the value obtained with paired recordings. The kinetics were quantified in 8 cells, by measuring the $20-80 \%$ rise time and the time constant of fast decay (see Materials and Methods).

On average, rise and decay times were slower for $\mathrm{GrC}$ - than $m f$-EPSCs $\left(\mathrm{t}_{20-80}, 0.3 \pm 0.2 \mathrm{~ms}\right.$ vs $0.1 \pm 0.03 \mathrm{~ms}, p=0.016$; fast decay time constant: $1.0 \pm 0.6 \mathrm{~ms}$ vs $0.4 \pm 0.1 \mathrm{~ms}, n=8$ cells, $p<$ 0.01 ). However, comparing rise time values within individual cells yielded contrasting results. In 3 of 8 cells, rise times were systematically longer in GrC-EPSCs than $m f$-EPSCs $(p<0.0001$ in each cell; mean $\mathrm{t}_{20-80}, 0.4 \pm 0.3 \mathrm{~ms}$ vs $0.1 \pm 0.03 \mathrm{~ms}$, "slowly rising GrC-EPSCs"; Fig. 7D, cell 1). In the remaining 5 cells, rise times were equally fast for GrC-EPSCs and $m f$-EPSCs $(p>0.05$ in each cell; mean $\mathrm{t}_{20-80}, 0.1 \pm 0.03 \mathrm{~ms}$ vs $0.1 \pm 0.03 \mathrm{~ms}$, "fastrising GrC-EPSCs"; Fig. 7E, cell 2). Mean decay times were $1.5 \pm$ $0.6 \mathrm{~ms}$ for slowly rising and $0.7 \pm 0.3 \mathrm{~ms}$ for fast-rising $\mathrm{GrC}$ EPSCs. In 2 of the 5 cells with fast-rising GrC-EPSCs, the decay phase of monosynaptic and disynaptic EPSCs were not significantly different $(p>0.2$; Fig. $7 E)$. Overall, the similarity of kinetic parameters of monosynaptic and disynaptic EPSCs in cells with fast-rising GrC-EPSCs suggests that, in those cells, both inputs were located at short electrotonic distance from the soma, and GrC-EPSCs arose from basolateral dendrites in the GL, at sites of contact with a GrC aa. In summary, we have shown that fast disynaptic EPSCs were present in the majority (5 of 8 ) of analyzed GoCs upon minimal stimulation of $m f$ afferents in the WM. The slow-rising disynaptic EPSCs were apparently less frequent ( 3 of 8 cells), although we cannot rule out that small, slow EPSCs were undetected in the baseline noise in these recordings. 
Overall, the results indicate that approximately half of the contacts of local GrCs onto GoCs are made by their aa on the basolateral dendrites.

\section{Discussion}

In this study, we combined morphological, imaging, and electrophysiological approaches to dissect the contribution of $m f$ and GrC excitatory inputs in controlling feedforward/feedback inhibitory circuits in the GL of the cerebellar cortex. We show, for the first time, that $a a$ of GrCs form functional synapses on the basolateral dendrites of GoCs in the GL.

GoC dendrites are confined within a parasagittal cerebellar module (Sillitoe et al., 2008), where they receive both local inputs from neurons within the module and distal inputs from other modules via the parallel fiber pathway. We found that aa synapses in the GL represent approximately half of all the contacts made by local GrCs on GoCs, the other half being formed in the ML by a and $p f$. The abundance of these local GrC connections constitutes the first evidence for a powerful, bona fide feedback inhibitory circuit in the GL.

We estimate that, during sustained $m f$ activity, the feedback circuit, via local $\mathrm{GrC}$ synapses, contributes approximately half of the excitatory synaptic charge transferred to GoCs. A large fraction of the corresponding EPSCs are produced at $a$ a synapses in the GL and are as fast as $m f$-EPSCs, arguing for a strong and temporally precise influence of this feedback inhibitory circuit over $\mathrm{GrC}$ population dynamics.

Quantitative evidence for a local feedback circuit in the GL

Previous studies of GrC inputs to GoCs mostly used extracellular stimulation in the ML (Bureau et al., 2000; Misra et al., 2000; Brickley et al., 2003; Watanabe and Nakanishi, 2003; Beierlein et al., 2007; Menuz et al., 2008; Robberechts et al., 2010), which does not allow separation of local from distal inputs. The ability to evoke EPSCs in GoCs through chemical GrC stimulation in parasagittal slices (Dieudonné, 1998) suggested the presence of local GrC-GoC contacts. We show here that $m f$ stimulation within a parasagittal cerebellar module evokes disynaptic local GrCEPSCs in GoCs. We establish the presence of this local feedback circuit in several steps. First, through EM analysis of stained GoC basolateral dendrites, we show that ascending $\mathrm{GrC}$ axons form synaptic $\mathrm{GrC}-\mathrm{GoC}$ contacts in the GL, confirming early morphological studies (in the rat: Palay and Chan-Palay, 1974, their Figs. 68, 99, and 115; in the turtle: Mugnaini et al., 1974). Second, we demonstrate by $\mathrm{Ca}^{2+}$ imaging that local $\mathrm{GrC}$ contacts on $\mathrm{GoC}$ basolateral dendrites form functional synapses (Fig. 4). Third, quantitative immunohistochemical analysis yields a lower estimate of 400 aa contacts/GoC in the GL (Fig. 5). Fourth, we found that EPSCs originating in the GL and ML can be distinguished upon their kinetics (Fig. 6). Examining the kinetics of local GrC EPSCs evoked by $m f$ stimulation or by loose-cell attached GrC stimulation, we conclude that $a a$ contacts in the GL represent approximately half of all local GrC-GoC contacts (Fig. 7). Hence, a GoC might receive as much as 800 contacts from local GrCs.

An upper limit to the number of distal $\mathrm{GrC}$ contacts is given by the number of $p f$ contacts to GoCs in the ML, derived from published data. The density of $p f$ varicosities synapsing on ML interneurons (MLIs) or GoC dendrites in the ML of adult rats is estimated to $2.66 \times 10^{7}$ boutons $/ \mathrm{mm}^{2}$ of Purkinje cell layer (Napper and Harvey, 1988). There are $\sim 42 \mathrm{MLIs} / \mathrm{GoC}$ in the cerebellar cortex (in the cat: $\sim 22$ MLIs/Purkinje cell, Palkovits et al., 1971; 1.9 Purkinje cells/ GoC, Lange, 1974). Assuming the dendritic surface of GoCs is twice that of MLIs (MLI capacitance: $\sim 20 \mathrm{pF}$; GoCs capacitance: $\sim 55 \mathrm{pF}$;
Dieudonné, 1998), $\sim 12 \times 10^{5} p f$ contacts $/ \mathrm{mm}^{2}$ of Purkinje cell layer $\left(2.66 \times 10^{7} \times 2 / 43\right)$ would be formed on GoCs. With $\sim 1000$ GoCs $/ \mathrm{mm}^{2}$ of Purkinje cell layer (Dugué et al., 2009), each GoC may receive $\sim 1200 p f$ contacts. Assuming a $1 \mathrm{~mm}$ total length for GoC apical dendrites, the density of $p f$ synapses would be similar to that found in MLIs (mean distance: $0.7 \mu \mathrm{m}$ ) (Abrahamsson et al., 2012). In conclusion, local $\mathrm{GrCs}$ within a $200 \mu \mathrm{m}$ parasagittal module may provide as many synaptic inputs to a $\mathrm{GoC}$ as the distal GrCs distributed along a $2 \mathrm{~mm} p f$ beam, suggesting a 10 times lower $p f$ connectivity.

\section{Synaptic properties of $\mathrm{GrC}$ and $m f$ afferences to GoCs}

GrC-EPSCs (Dieudonné, 1998; Bureau et al., 2000; Misra et al., 2000; Kanichay and Silver, 2008) and $m f$-EPSCs (Kanichay and Silver, 2008) (Fig. 1) recorded from GoCs at hyperpolarized potentials are mediated by AMPARs. Our data show that unitary $m f$ inputs transfer three times the charge of unitary GrC inputs ( $\sim 155 \mathrm{fC}$ vs $\sim 55 \mathrm{fC})$, probably because of the presence of multiple sites of contact between $m f s$ and GoCs within glomeruli (Fig. $3 A, C)$. Both $\mathrm{GrC}-\mathrm{GoC}$ and $m f-\mathrm{GoC}$ connections can display widely variable paired-pulse plasticity. The absence of monosynaptic EPSCs presenting the characteristic paired-pulse depression, observed at CF inputs to Purkinje cells (Konnerth et al., 1990) and to MLIs (Szapiro and Barbour, 2007), argues against the presence of functional CF-GoC inputs. Despite the morphological description of contacts made on GoC somata by thin CF collaterals (Hamori and Szentagothai, 1966; Eccles et al., 1967; Chan-Palay and Palay, 1971; Altman and Bayer, 1997; Sugihara et al., 1999; but see Galliano et al., 2013), the existence of functional CF-GoC inputs remains unlikely, as also suggested by the depression of GoC firing evoked by in vivo stimulations of olivary neurons or CFs (Schulman and Bloom, 1981; Xu and Edgley, 2008).

AMPAR-mediated $m f$-EPSCs commonly showed biphasic decay, the slow component transferring 55\% of the EPSC charge. The role of glutamate spillover in generating this component remains unclear. At $m f$-GrC (DiGregorio et al., 2002) and GoCGrC (Rossi and Hamann, 1998) contacts, isolated slow synaptic currents resulting from pure spillover were observed, whereas they were scarce at $m f-G o C$ contacts; this may result from morpho-functional peculiarities of the $m f$-GoC synapse (Fig. $3 A-C)$ (Kanichay and Silver, 2008, their Discussion). Alternatively, perisynaptic kainate receptors (Bureau et al., 2000), rather than spillover, may explain the slow $m f$-EPSC component in GoCs. A slow component was not detected in paired GrC-GoC recordings but was present in minimal $p f$ stimulations.

We show here, for the first time, that AMPARs present at the $p f$ synapse are strongly $\mathrm{Ca}^{2+}$ permeable (Fig. 6). A small and variable D-APV-resistant $\mathrm{Ca}^{2+}$ influx component was also recorded at some $m f$ synapses. The degree of $\mathrm{Ca}^{2+}$ permeability of AMPARs at different synapses may be regulated by $\gamma 2-3$ TARPs, which control the synaptic expression of AMPARs in GoCs (Menuz et al., 2008). An NMDAR-mediated component of GrC-EPSCs was described in immature GoCs (Misra et al., 2000; Brickley et al., 2003) but was highly variable in more mature GoCs, both in chemically evoked GrCEPSCs (Dieudonné, 1998) and in GrC-GoC pairs (data not shown). In contrast, all $m f$ contacts displayed a strongly $\mathrm{Mg}^{2+}$-sensitive NMDAR-mediated component (Fig. 1); its role in physiological conditions, however, remains to be determined. Differential mechanisms of $\mathrm{Ca}^{2+}$ signaling at $\mathrm{GrC}$ and $m f$ synapses need to be further studied in relation with plasticity (Kelly et al., 2009; Robberechts et al., 2010). 


\section{Physiological implications of a feedback inhibitory circuit in the cerebellar GL \\ GoC apical dendrites exert low-pass filtering on $p f$-EPSCs (Fig. 6)} (Vervaeke et al., 2012), whereas basolateral dendrites operate more modest filtering (Fig. 6) (Kanichay and Silver, 2008). Local GrC-EPSCs can display similar kinetics as $m f$-EPSCs (Figs. 6 and 7 ), as expected from aa synapse location on basolateral GoC dendrites. The fast kinetics of $m f$-EPSCs was proposed to enhance the temporal precision of GoC spiking upon synchronization of $\sim 4$ inputs (Kanichay and Silver, 2008). However, submillisecond $m f$ synchronization is unlikely in physiological conditions. We show here that monosynaptic $m f$-EPSCs are followed within a millisecond by disynaptic local GrC-EPSCs, transferring on average, during an input burst, a similar charge as $m f$-EPSCs (Fig. 2). Given the density of $\mathrm{GrCs}\left(2 \times 10^{6} \mathrm{GrC} / \mu \mathrm{l}\right.$ in the rat) (Harvey and Napper, 1988) and the GL volume occupied by a GoC dendritic arbor $\left(\sim 200 \times 100 \times 180 \mu \mathrm{m} \sim 4 \times 10^{-3} \mu \mathrm{l}\right)$ (Dieudonné, 1998; Barmack and Yakhnitsa, 2008), approximately one-tenth of local GrCs (800 of 8000) may be connected to each GoC. A single $m f$ contacts $\sim 53 \mathrm{GrCs} /$ glomerulus (Jakab and Hamori, 1988) and may form $\sim 2$ or 3 glomeruli inside the GL volume spanned by a GoC dendritic arbor (Palay and Chan-Palay, 1974; their Fig. 126 ), therefore contacting $\sim 100-150$ GrCs and potentially synchronizing 10-15 disynaptic $\mathrm{GrC}$ inputs to the GoC. We propose that these synchronized disynaptic EPSCs are essential components of the computational unit driving GoC firing during a $m f$ input burst. A similar clustered organization was recently shown to optimize passage-of-time encoding by GL dynamics (Yamazaki and Tanaka, 2007).

Computer models of the GL have often used unrealistically high (Maex and De Schutter, 1998) or low (Medina et al., 2000; Kalmbach et al., 2011) levels of $p f$-GoC connections. Interestingly, decreasing GrC-GoC connectivity to $10 \%$ (Simoes de Souza and De Schutter, 2011), the value estimated here for local GrC connectivity, generates gap junction-dependent weak synchronization as observed in situ (Dugué et al., 2009). In addition, weak common $p$ finputs (Maex et al., 2000) are thought to explain GoC synchrony in longitudinally aligned pairs (Vos et al., 1999b). More efforts toward realistic GL models were made recently (Gleeson et al., 2007; Solinas et al., 2010) and should generate further insights on GL dynamics within and across cerebellar modules.

\section{References}

Abrahamsson T, Cathala L, Matsui K, Shigemoto R, Digregorio DA (2012) Thin dendrites of cerebellar interneurons confer sublinear synaptic integration and a gradient of short-term plasticity. Neuron 73:1159-1172. CrossRef Medline

Albus JS (1971) A theory of cerebellar function. Math Biosci 10:26-61.

Altman J, Bayer SA (1997) Development of the cerebellar system in relation to its evolution, structure and functions. Boca Raton, FL: CRC.

Apps R, Hawkes R (2009) Cerebellar cortical organization: a one-map hypothesis. Nat Rev Neurosci 10:670-681. CrossRef Medline

Barbour B, Isope P (2000) Combining loose cell-attached stimulation and recording. J Neurosci Methods 103:199-208. CrossRef Medline

Barmack NH, Yakhnitsa V (2008) Functions of interneurons in mouse cerebellum. J Neurosci 28:1140-1152. CrossRef Medline

Beierlein M, Fioravante D, Regehr WG (2007) Differential expression of posttetanic potentiation and retrograde signaling mediate targetdependent short-term synaptic plasticity. Neuron 54:949-959. CrossRef Medline

Brickley SG, Misra C, Mok MH, Mishina M, Cull-Candy SG (2003) NR2B and NR2D subunits coassemble in cerebellar Golgi cells to form a distinct NMDA receptor subtype restricted to extrasynaptic sites. J Neurosci 23: 4958-4966. Medline

Bureau I, Dieudonne S, Coussen F, Mulle C (2000) Kainate receptor- mediated synaptic currents in cerebellar Golgi cells are not shaped by diffusion of glutamate. Proc Natl Acad Sci U S A 97:6838-6843. CrossRef Medline

Chan-Palay V, Palay SL (1971) Tendril and glomerular collaterals of climbing fibers in the granular layer of the rat's cerebellar cortex. Z Anat Entwicklungsgesch 133:247-273. CrossRef Medline

Crowley JJ, Fioravante D, Regehr WG (2009) Dynamics of fast and slow inhibition from cerebellar Golgi cells allow flexible control of synaptic integration. Neuron 63:843-853. CrossRef Medline

D'Angelo E, De Zeeuw CI (2009) Timing and plasticity in the cerebellum: focus on the granular layer. Trends Neurosci 32:30-40. CrossRef Medline

D’Angelo E, De Filippi G, Rossi P, Taglietti V (1995) Synaptic excitation of individual rat cerebellar granule cells in situ: evidence for the role of NMDA receptors. J Physiol 484:397-413. Medline

Dieudonné S (1998) Submillisecond kinetics and low efficacy of parallel fibre-Golgi cell synaptic currents in the rat cerebellum. J Physiol 510:845866. CrossRef Medline

DiGregorio DA, Nusser Z, Silver RA (2002) Spillover of glutamate onto synaptic AMPA receptors enhances fast transmission at a cerebellar synapse. Neuron 35:521-533. CrossRef Medline

Dugué GP, Dumoulin A, Triller A, Dieudonné S (2005) Target-dependent use of co-released inhibitory transmitters at central synapses. J Neurosci 25:6490-6498. CrossRef Medline

Dugué GP, Brunel N, Hakim V, Schwartz E, Chat M, Lévesque M, Courtemanche R, Léna C, Dieudonné S (2009) Electrical coupling mediates tunable low-frequency oscillations and resonance in the cerebellar Golgi cell network. Neuron 61:126-139. CrossRef Medline

Dumoulin A, Triller A, Dieudonné S (2001) IPSC kinetics at identified GABAergic and mixed GABAergic and glycinergic synapses onto cerebellar Golgi cells. J Neurosci 21:6045-6057. Medline

Eccles JC, Ito M, Szentagothai J (1967) The cerebellum as a neuronal machine. New York: Springer Verlag.

Edgley SA, Lidierth M (1987) The discharges of cerebellar Golgi cells during locomotion in the cat. J Physiol 392:315-332. Medline

Forti L, Cesana E, Mapelli J, D'Angelo E (2006) Ionic mechanisms of autorhythmic firing in rat cerebellar Golgi cells. J Physiol 574:711-729. CrossRef Medline

Fremeau RT Jr, Troyer MD, Pahner I, Nygaard GO, Tran CH, Reimer RJ, Bellocchio EE, Fortin D, Storm-Mathisen J, Edwards RH (2001) The expression of vesicular glutamate transporters defines two classes of excitatory synapse. Neuron 31:247-260. CrossRef Medline

Galliano E, Baratella M, Sgritta M, Ruigrok THJ, Haasdijk, Hoebeek FR, D’Angelo E, Jaarsma D, De Zeeuw CI (2013) Anatomical investigation of potential contacts between climbing fibers and cerebellar Golgi cells in the mouse. Front Neural Circuits 7:59. CrossRef Medline

Gardner-Medwin AR (1972) An extreme supernormal period in cerebellar parallel fibres. J Physiol 222:357-371. Medline

Gebre SA, Reeber SL, Sillitoe RV (2012) Parasagittal compartmentation of cerebellar mossy fibers as revealed by the patterned expression of vesicular glutamate transporters VGLUT1 and VGLUT2. Brain Struct Funct 217: 165-180. CrossRef Medline

Gleeson P, Steuber V, Silver RA (2007) neuroConstruct: a tool for modeling networks of neurons in 3D space. Neuron 54:219-235. CrossRef Medline

Hamann M, Rossi DJ, Attwell D (2002) Tonic and spillover inhibition of granule cells control information flow through cerebellar cortex. Neuron 33:625-633. CrossRef Medline

Hámori J, Szentágothai J (1966) Identification under the electron microscope of climbing fibers and their synaptic contacts. Exp Brain Res 1:65-81. Medline

Harvey RJ, Napper RM (1988) Quantitative study of granule and Purkinje cells in the cerebellar cortex of the rat. J Comp Neurol 274:151-157. CrossRef Medline

Heine SA, Highstein SM, Blazquez PM (2010) Golgi cells operate as statespecific temporal filters at the input stage of the cerebellar cortex. J Neurosci 30:17004-17014. CrossRef Medline

Hioki H, Fujiyama F, Taki K, Tomioka R, Furuta T, Tamamaki N, Kaneko T (2003) Differential distribution of vesicular glutamate transporters in the rat cerebellar cortex. Neuroscience 117:1-6. CrossRef Medline

Hisano S, Sawada K, Kawano M, Kanemoto M, Xiong G, Mogi K, SakataHaga H, Takeda J, Fukui Y, Nogami H (2002) Expression of inorganic phosphate/vesicular glutamate transporters (BNPI/VGLUT1 and DNPI/ 
VGLUT2) in the cerebellum and precerebellar nuclei of the rat. Brain Res Mol Brain Res 107:23-31. CrossRef Medline

Holtzman T, Rajapaksa T, Mostofi A, Edgley SA (2006) Different responses of rat cerebellar Purkinje cells and Golgi cells evoked by widespread convergent sensory inputs. J Physiol 574:491-507. CrossRef Medline

Holtzman T, Sivam V, Zhao T, Frey O, van der Wal PD, de Rooij NF, Dalley JW, Edgley SA (2011) Multiple extra-synaptic spillover mechanisms regulate prolonged activity in cerebellar Golgi cell-granule cell loops. J Physiol 589:3837-3854. CrossRef Medline

Hull C, Regehr WG (2012) Identification of an inhibitory circuit that regulates cerebellar Golgi cell activity. Neuron 73:149-158. CrossRef Medline

Jakab RL, Hámori J (1988) Quantitative morphology and synaptology of cerebellar glomeruli in the rat. Anat Embryol (Berl) 179:81-88. CrossRef Medline

Kalmbach BE, Voicu H, Ohyama T, Mauk MD (2011) A subtraction mechanism of temporal coding in cerebellar cortex. J Neurosci 31:2025-2034. CrossRef Medline

Kanichay RT, Silver RA (2008) Synaptic and cellular properties of the feedforward inhibitory circuit within the input layer of the cerebellar cortex. J Neurosci 28:8955-8967. CrossRef Medline

Katz B (1969) The release of neural transmitter substances. Liverpool: Liverpool UP.

Kelly L, Farrant M, Cull-Candy SG (2009) Synaptic mGluR activation drives plasticity of calcium-permeable AMPA receptors. Nat Neurosci 12:593601. CrossRef Medline

Konnerth A, Llano I, Armstrong CM (1990) Synaptic currents in cerebellar Purkinje cells. Proc Natl Acad Sci U S A 87:2662-2665. CrossRef Medline

Kudoh SN, Taguchi T (2002) A simple exploratory algorithm for the accurate and fast detection of spontaneous synaptic events. Biosens Bioelectron 17:773-782. CrossRef Medline

Lange W (1974) Regional differences in the distribution of Golgi cells in the cerebellar cortex of man and some other mammals. Cell Tissue Res 153: 219-226. Medline

Llinas R (1982) General discussion: radial connectivity in the cerebellar cortex: a novel view regarding the functional organization of the molecular layer. In: The cerebellum: new vistas (Palay SL, Chan-Palay V, eds), pp 189-194. Berlin: Springer.

Maex R, De Schutter E (1998) Synchronization of Golgi and granule cell firing in a detailed network model of the cerebellar granule cell layer. J Neurophysiol 80:2521-2537. Medline

Maex R, Vos BP, De Schutter E (2000) Weak common parallel fibre synapses explain the loose synchrony observed between rat cerebellar Golgi cells. J Physiol 523:175-192. CrossRef Medline

Mapelli J, D'Angelo E (2007) The spatial organization of long-term synaptic plasticity at the input stage of cerebellum. J Neurosci 27:1285-1296. CrossRef Medline

Marcaggi P, Billups D, Attwell D (2003) The role of glial glutamate transporters in maintaining the independent operation of juvenile mouse cerebellar parallel fibre synapses. J Physiol 552:89-107. CrossRef Medline

Marr D (1969) A theory of cerebellar cortex. J Physiol 202:437-470. Medline

Medina JF, Garcia KS, Nores WL, Taylor NM, Mauk MD (2000) Timing mechanisms in the cerebellum: testing predictions of a large-scale computer simulation. J Neurosci 20:5516-5525. Medline

Menuz K, O’Brien JL, Karmizadegan S, Bredt DS, Nicoll RA (2008) TARP redundancy is critical for maintaining AMPA receptor function. J Neurosci 28:8740-8746. CrossRef Medline

Misra C, Brickley SG, Farrant M, Cull-Candy SG (2000) Identification of subunits contributing to synaptic and extrasynaptic NMDA receptors in Golgi cells of the rat cerebellum. J Physiol 524:147-162. CrossRef Medline

Mugnaini E, Atluri RL, Houk JC (1974) Fine structure of granular layer in turtle cerebellum with emphasis on large glomeruli. J Neurophysiol 37:1-29. Medline

Napper RM, Harvey RJ (1988) Number of parallel fiber synapses on an individual Purkinje cell in the cerebellum of the rat. J Comp Neurol 274:168-177. CrossRef Medline

Otsu Y, Bormuth V, Wong J, Mathieu B, Dugué GP, Feltz A, Dieudonné S (2008) Optical monitoring of neuronal activity at high frame rate with a digital random-access multiphoton (RAMP) microscope. J Neurosci Methods 173:259-270. CrossRef Medline

Palay SL, Chan-Palay V (1974) Cerebellar cortex. New York: Springer.

Palkovits M, Magyar P, Szentágothai J (1971) Quantitative histological analysis of the cerebellar cortex in the cat: 3 . Structural organization of the molecular layer. Brain Res 34:1-18. CrossRef Medline

Pichitpornchai C, Rawson JA, Rees S (1994) Morphology of parallel fibres in the cerebellar cortex of the rat: an experimental light and electron microscopic study with biocytin. J Comp Neurol 342:206-220. CrossRef Medline

Prsa M, Dash S, Catz N, Dicke PW, Thier P (2009) Characteristics of responses of Golgi cells and mossy fibers to eye saccades and saccadic adaptation recorded from the posterior vermis of the cerebellum. J Neurosci 29:250-262. CrossRef Medline

Reynolds ES (1963) The use of lead citrate at high $\mathrm{pH}$ as an electron-opaque stain in electron microscopy. J Cell Biol 17:208-212. CrossRef Medline

Robberechts Q, Wijnants M, Giugliano M, De Schutter E (2010) Long-term depression at parallel fiber to Golgi cell synapses. J Neurophysiol 104: 3413-3423. CrossRef Medline

Ros H, Sachdev RN, Yu Y, Sestan N, McCormick DA (2009) Neocortical networks entrain neuronal circuits in cerebellar cortex. J Neurosci 29: 10309-10320. CrossRef Medline

Rossi DJ, Hamann M (1998) Spillover-mediated transmission at inhibitory synapses promoted by high affinity alpha6 subunit GABA(A) receptors and glomerular geometry. Neuron 20:783-795. CrossRef Medline

Schulman JA, Bloom FE (1981) Golgi cells of the cerebellum are inhibited by inferior olive activity. Brain Res 210:350-355. CrossRef Medline

Schwartz EJ, Rothman JS, Dugué GP, Diana M, Rousseau C, Silver RA, Dieudonné S (2012) NMDA receptors with incomplete $\mathrm{Mg}(2)(+)$ block enable low-frequency transmission through the cerebellar cortex. J Neurosci 32:6878-6893. CrossRef Medline

Sillitoe RV, Chung SH, Fritschy JM, Hoy M, Hawkes R (2008) Golgi cell dendrites are restricted by Purkinje cell stripe boundaries in the adult mouse cerebellar cortex. J Neurosci 28:2820-2826. CrossRef Medline

Simat M, Parpan F, Fritschy JM (2007) Heterogeneity of glycinergic and GABAergic interneurons in the granule cell layer of mouse cerebellum. J Comp Neurol 500:71-83. CrossRef Medline

Simões de Souza FM, De Schutter E (2011) Robustness effect of gap junctions between Golgi cells on cerebellar cortex oscillations. Neural Syst Circuits 1:7. CrossRef Medline

Solinas S, Nieus T, D'Angelo E (2010) A realistic large-scale model of the cerebellum granular layer predicts circuit spatio-temporal filtering properties. Front Cell Neurosci 4:12. CrossRef Medline

Sugihara I, Wu H, Shinoda Y (1999) Morphology of single olivocerebellar axons labeled with biotinylated dextran amine in the rat. J Comp Neurol 414:131-148. CrossRef Medline

Szapiro G, Barbour B (2007) Multiple climbing fibers signal to molecular layer interneurons exclusively via glutamate spillover. Nat Neurosci 10: 735-742. CrossRef Medline

Takamori S (2006) VGLUTs: 'exciting' times for glutamatergic research? Neurosci Res 55:343-351. CrossRef Medline

van Kan PL, Gibson AR, Houk JC (1993) Movement-related inputs to intermediate cerebellum of the monkey. J Neurophysiol 69:74-94. Medline

Varoqui H, Schäfer MK, Zhu H, Weihe E, Erickson JD (2002) Identification of the differentiation-associated $\mathrm{Na}+/ \mathrm{PI}$ transporter as a novel vesicular glutamate transporter expressed in a distinct set of glutamatergic synapses. J Neurosci 22:142-155. Medline

Vervaeke K, Lorincz A, Gleeson P, Farinella M, Nusser Z, Silver RA (2010) Rapid desynchronization of an electrically coupled interneuron network with sparse excitatory synaptic input. Neuron 67:435-451. CrossRef Medline

Vervaeke K, Lorincz A, Nusser Z, Silver RA (2012) Gap junctions compensate for sublinear dendritic integration in an inhibitory network. Science 335:1624-1628. CrossRef Medline

Vos BP, Volny-Luraghi A, De Schutter E (1999a) Cerebellar Golgi cells in the rat: receptive fields and timing of responses to facial stimulation. Eur J Neurosci 11:2621-2634. CrossRef Medline

Vos BP, Maex R, Volny-Luraghi A, De Schutter E (1999b) Parallel fibers synchronize spontaneous activity in cerebellar Golgi cells. J Neurosci 19:RC6. Medline

Watanabe D, Nakanishi S (2003) mGluR2 postsynaptically senses granule cell inputs at Golgi cell synapses. Neuron 39:821-829. CrossRef Medline

Watanabe D, Inokawa H, Hashimoto K, Suzuki N, Kano M, Shigemoto R, Hirano T, Toyama K, Kaneko S, Yokoi M, Moriyoshi K, Suzuki M, Kobayashi K, Nagatsu T, Kreitman RJ, Pastan I, Nakanishi S (1998) Ablation of cerebellar Golgi cells disrupts synaptic integration involving 
GABA inhibition and NMDA receptor activation in motor coordination. Cell 95:17-27. CrossRef Medline

Xu W, Edgley SA (2008) Climbing fibre-dependent changes in Golgi cell responses to peripheral stimulation. J Physiol 586:4951-4959. CrossRef Medline

Xu W, Edgley SA (2010) Cerebellar Golgi cells in the rat receive convergent peripheral inputs via a lateral reticular nucleus relay. Eur J Neurosci 32: 591-597. CrossRef Medline
Yamazaki T, Tanaka S (2007) A spiking network model for passage-of-time representation in the cerebellum. Eur J Neurosci 26:2279-2292. CrossRef Medline

Zeilhofer HU, Studler B, Arabadzisz D, Schweizer C, Ahmadi S, Layh B, Bösl MR, Fritschy JM (2005) Glycinergic neurons expressing enhanced green fluorescent protein in bacterial artificial chromosome transgenic mice. J Comp Neurol 482:123-141. CrossRef Medline 